\title{
EL NÚCLEO DE INSTITUCIONES CIENTÍFICAS MATRITENSES EN EL PASEO DEL PRADO DESDE EL SIGLO XVIII
}

\author{
Luis Alfredo Baratas Díaz \\ Dpto. de Biología Celular - Facultad de Biología - Universidad Complutense, Madrid
}

\section{RESUMEN}

A lo largo de la segunda mitad del siglo XVIII se constituyó en torno al actual Paseo del Prado un importante núcleo de instituciones científicas (Real Jardín Botánico, Academia de Ciencias, Observatorio Astronómico, Hospital General,...). El desarrollo de este foco científico sufrió las vicisitudes y limitaciones que afectaron a la política científica ilustrada. En el siglo XIX el establecimiento de nuevos centros docentes en esta zona fue escaso y carente de una idea directriz; los diversos proyectos para edificar una Facultad de Ciencias o la Escuela de Artes y Oficios limitaron considerablemente la extensión del Real Jardín. En el primer tercio del siglo XX la actividad constructora se limitaría a las obras en el Instituto Cajal (plagadas de malentendidos y desajustes) y unas constantes obras de remodelación en el Museo Velasco y el Jardín Botánico.

\section{SUMMARY}

Throughout second half of 18th century was constituted a scientific institutions centre around the "Paseo del Prado' (Royal Botanical Garden, Sciences Academy, Astronomic Observatory, General Hospital,...). The development of this scientific area suffered the vicissitudes and limitations that affected to the illustrated scientific policy. In 19th century the new educational and research centers establishment was scarce and laking of clear guidelines; the various projects to build a Sciences Faculty or the Arts and Trades School limited considerably the extension of the Royal Garden. In the first third of 20th century the constructing activity would be limited to the works in the Cajal Institute (plagued by misundestanding and upsetting) and some constant remodeling works in the Velasco Museum and Royal Garden.

\section{INTRODUCCIÓN}

Es un tópico, con la indudable parte de verdad que subyace a los tópicos, considerar a Carlos III como el mejor Alcalde de Madrid. Habitual, asimismo, es referirse a él como promotor de un amplio programa de fomento de la ciencia en la España de la segunda mitad del siglo XVIII. Si hay un espacio físico en que ambas facetas de la 


\section{LUIS ALFREDO BARATAS DÍAZ}

labor regia coinciden éste es, sin duda, la intersección de los Paseos del Prado y de Atocha. En éste área confluyen simultáneamente los esfuerzos por embellecer el entorno urbano de la capital y por establecer los centros en los que la actividad científica debía desarrollarse (baste citar, a modo de ejemplo, la instalación del Real Jardín Botánico).

El desarrollo de éste núcleo de instituciones científicas entre los siglos XVIII y $\mathrm{XX}$ es un perfecto ejemplo del irregular devenir de la ciencia en la España contemporánea; ilustrando por igual la grandeza y altitud de miras de algunos de nuestros gestores científicos, con la incoherencia y la falta de iniciativa de otros.

\section{LAS INSTITUCIONES CIENTÍFICAS EN TORNO AL PASEO DEL PRADO EN EL SIGLO XVIII}

A lo largo del siglo XVIII, pero especialmente durante el reinado de Carlos III, la ciudad fue mejorando su aspecto gracias al cumplimiento de las ordenanzas de alumbrado, limpieza y pavimentación, pero no se acometieron reformas urbanísticas de entidad en su primitivo núcleo; ḥubo, sí, nuevas construcciones (por ejemplo el Hospicio, la Casa del Correo o de la Aduana) pero no significaron un replanteamiento urbanístico del trazado del Madrid de los Austrias' ${ }^{1}$.

La actuación urbanística bajo Carlos III se orientó fundamentalmente hacia la periferia; la creación o remodelación de paseos (constituyéndose un primer cinturón alrededor del recinto) y el establecimiento de puertas de entrada (la Puerta de Alcalá será el ejemplo más notable) fueron las aportaciones más significativas ${ }^{2}$. La construcción del nuevo Palacio Real, y el forzoso traslado del Rey al Palacio del Buen Retiro, contribuyeron a desplazar el centro de gravedad de la ciudad hacia al este, dando al Paseo del Prado una mayor relevancia ${ }^{3}$.

El Paseo del Prado, o Salón del Prado como era llamado a finales del XVIII, es el trazado urbano más ambicioso y paradigmático de los diseñados en este período. La

I Véase: Muro García-Villalba, F. y Rivas Quinzaños, P. (1984), «Proyecto y realidad en la construcción del Madrid borbónico», en Madrid y los Borbones en el siglo XVIII. La construcción de una ciudad y su territorio, CAM, Madrid, pp.87-88; y GARCíA FELGUERA, M.S. (1979), «La intervención de Carlos III en Madrid. Carácter de la reforma interior», Revista de la Universidad Complutense, vol. XXVIII, n ${ }^{\circ} 115$, pp.483-484.

2 Véanse MuRo, F. y RiVAS, P. (1984), p.88; ChUECA GoITIA, F. (1968), «La época de los Borbones», en Resumen histórico del urbanismo en España, Instituto de Estudios de Administración Local, Madrid, pp.225-228; y Domínguez Díez, R. y Gallego GarCía, A. (1983), «Carlos III y la remodelación de Madrid como reflejo de los presupuestos urbanísticos de la Ilustración», Estudios Territoriales, $\mathrm{n}^{\circ} 10$, abril-junio, pp.141-147.

3 Véase SAMBRICIO, C. (1977), «Notas sobre la evolución del espacio urbano y la Ilustración», Arquitectura, $\mathrm{n}^{\circ} 203,1977, \mathrm{p} .68$. 


\section{EL NÚCLEO DE INSTITUCIONES CIENTÍFICAS MATRITENSES EN EL PASEO DEL PRADO}

delimitación del Salón fue proyectada por José de Hermosilla en 1767, comenzando las obras en 1775 y finalizando en 1782; las fuentes ornamentales fueron diseñadas por Ventura Rodríguez en 1777 y su finalización coincidió con la del Salón ${ }^{4}$. Como ha señalado Fernández Alba, el Salón se concebía como un parque cortesano, interrumpido por una secuencia de plazas circulares, en el cual arbolado y elementos naturales se integraban con grandes edificios públicos adyacentes; además, el Salón confirió al Madrid del futuro una nueva linealidad, norte-sur, frente a la antigua concentración alrededor de un núcleo central, típica del Madrid de los Austrias ${ }^{5}$. Elemento urbanístico de principal importancia en el diseño del Salón del Prado era el carácter monumental de los edificios próximos; aparecen así, en la vertiente este del paseo dos grandes construcciones, auténticas joyas de la arquitectura dieciochesca: el Real Jardín Botánico y el futuro Museo del Prado. Significativamente, como prueba de la importancia que en el período ilustrado alcanza la ciencia, ambos edificios estuvieron destinados originariamente a albergar instituciones científicas.

El traslado del Real Jardín Botánico al Paseo del Prado, desde su antiguo emplazamiento de Migas Calientes junto a la ribera del Manzanares, se inició tras una Real Orden dada el 25 de julio de 1774 por Carlos III. La construcción del nuevo recinto, como ha mostrado Carmen Añón, fue encomendada al arquitecto italiano Francisco Sabatini. Sabatini organizó el Jardín en dos áreas, una ajardinada o cuerpo principal (que todavía se conserva) y otra complementaria dedicada a huerto y viveros, que se extendía hasta el Paseo de Atocha (actual Paseo de la Infanta Isabel); y fue responsable, asimismo, del cerramiento del recinto y de la estructuración de la porción ajardinada en tres bancales para salvar el desnivel del solar ${ }^{6}$. También propondría una distribución interior de las parcelas ajardinadas, que Añón valora muy negativamente, que fue desestimada, no pudiendo responsabilizarse del diseño definitivo ni a Sabatini ni a Villanueva, a quién tradicionalmente se ha atribuido ${ }^{7}$. De forma simultánea se realizaría el traslado de las plantas desde el antiguo jardín (iniciado en 1777), inaugurándose el nuevo recinto en 1781 , coincidiendo prácticamente con el fin de las obras en el Salón del Prado. En años sucesivos se acometerían obras de acondicionamiento y mejora en el Jardín: la construcción de los Invernáculos de Poniente, conocido actualmente como Pabellón Villanueva (1781), construcción de la Puerta de Murillo (1785), de los emparrados de los paseos laterales (1786) y de la

\footnotetext{
4 Véase VVAA (1987), Guía de Arquitectura y Urbanismo de Madrid, Colegio Oficial de Arquitectos de Madrid, Madrid, t.I, pp.161-162.

5 Véase FERNÁNDEZ ALBA, A. (983), «El Pabellón de Invernáculos, noticia de una restitución histórica», en Añón, C.; CASTRoviejo, S.; Fernández DE AlBA, A.; Real Jardín Botánico de Madrid, Pabellón de Invernáculos. (Noticias de una restitución histórica), CSIC, Madrid, pp.106-107.

6 Véase AÑón, C. (1987), Real Jardín Botánico de Madrid. Sus orígenes: I755-1781, CSIC, Madrid, pp.47-55.

7 Ibidem, pp.55-56 y 59-61.
} 


\section{LUIS ALFREDO BARATAS DÍAZ}

Cátedra Cavanilles (1794) ${ }^{8}$. A finales del siglo XVIII, por tanto, el Jardín tenía la estructura, extensión y, excepción hecha de las estufas, los edificios principales con los que contó hasta finales del siglo XIX y que suponían el límite sud-oriental del Paseo del Prado y el centro del área científica aquí estudiada.

El acondicionamiento del Salón del Prado y la presencia del Real Jardín Botánico fueron factores determinantes para decidir la instalación de la Academia de Ciencias (el actual Museo del Prado). El proyecto de constitución de una asamblea de hombres de ciencia y letras se remontaba al reinado del primer Borbón, Felipe V, y tuvo continuidad, también fallida, durante el reinado de Fernando VI. Sería bajo el reinado de Carlos III, potenciado por el Conde de Floridablanca, a la sazón Ministro de Estado, cuando el proyecto de Academia de Ciencias tomase definitiva entidad. Entre 1779 y 1780 Bernardo y Tomás Iriarte realizaron diversos informes sobre la estructura de la Academia, proponiendo una institución de carácter generalista, que englobaba en un sólo organismo los diversos ramos del conocimiento. Frente a este modelo, Floridablanca se inclinaba por una institución dedicada exclusivamente al desarrollo de la actividad científica. La propuesta del ministro fue la que prosperó finalmente y en 1785 se encargó a Juan de Villanueva la construcción de un edificio sede de la institución, presentándose a valoración real dos proyectos. El proyecto definitivo estaba constituido por tres cuerpos unidos mediante dos galerías; considerando el proyecto de Academia de Ciencias como una institúción de investigación, docencia y exhibición, y a pesar de la falta de Memoria descriptiva del edificio, cabe pensar que el cuerpo central, formado por un grandioso paraninfo académico, estaba destinado a las reuniones plenarias de la Academia, mientras que las galerías estarían dedicadas a la exposición de objetos científicos y naturales (fundamentalmente las colecciones del Gabinete de Historia Natural), y los palacios laterales, concebidos como construcciones anejas y casi independientes, a laboratorios y aulas ${ }^{9}$.

El proceso de construcción del edificio sufrió diversos avatares y se constituyó en un elemento de la lucha política y la campaña de desprestigio contra Floridablanca, que terminó con la destitución del ministro en 1792. Durante el corto ministerio del Conde de Aranda, poco se avanzó en el edificio de la Academia, y la situación empeoró bajo Godoy, quién prodigó las obstrucciones al desarrollo de la institución. Rumeu cita un documento firmado por Godoy en 1796, ante un intento de revitalizar el desarrollo de la Academia, que dice:

8 Véase FERnÁNDEZ AlbA, A. (1983), pp.110-111.

9 Véase: Rumeu de Armas, A. (1980), Origen y fundación del Museo del Prado, Instituto de España, Madrid, pp.36-39. 


\section{EL NÚCLEO DE INSTITUCIONES CIENTÍFICAS MATRITENSES EN EL PASEO DEL PRADO}

\footnotetext{
«Póngase todo con el expediente. Pero ciertamente que en mi tiempo no se verá concluido el establecimiento. Los abusos en él y los excesos de cada particular son consiguientes quando se amplía la facultad de lucir el talento, la energía, elegancia, etc.»11)
}

No obstante, a pesar de las dificultades que enfrentó la non-nata Academia, el edificio que debía ser su sede si fue completado. Varios testimonios indican que a finales del siglo XVIII el edificio estaba muy avanzado y con casi total seguridad estaba finalizado en 1808. Los acontecimientos bélicos y el abandono determinaron su ruina parcial; al restaurarse la dinastía borbónica tras la guerra se rehabilitó el edificio y, retomando antiguas propuestas dieciochescas y de la monarquía josefina, se destinó a Museo de Pinturas.

Otra dependencia científica de este núcleo fue el Observatorio Astronómico. Sugerido su establecimiento por Jorge Juan al rey Carlos III, éste encargo su erección a Juan de Villanueva. La construcción se inició en 1790, bajo el reinado de Carlos IV, en el Cerro de San Blas, cercano al límite este del Real Jardín Botánico. Aunque el edificio no estaba terminado todavía en 1799 , ya era utilizado para actividades docentes; la instalación de material científico para investigación se realizó a lo largo de la primera década del siglo XIX. Desgraciadamente cuando el Observatorio estaba a punto de ser finalizado, el estallido de la Guerra de la Independencia determinó su abandono y saqueo ${ }^{11}$.

Otra institución científica próxima a este área fue el Real Gabinete de Máquinas. En abril de 1788 el embajador español en Francia, Fernán Nuñez, propuso la creación de un 'gabinete de máquinas' en que depositar la colección de planos y maquetas que habían formado un grupo de pensionados españoles en París. En diciembre de ese mismo año se nombraba a Agustín de Betancourt, responsable del grupo de pensionados, director del Real Gabinete de Máquinas. Los primeros planos y maquetas llegaron a Madrid en 1791, instalándose en el ala sur del palacio del Buen Retiro, abriéndose el Gabinete al público el 1 de abril de 1792. Posteriormente, al hacerse cargo Betancourt de la Inspección General de Caminos y Canales (1801), uno de sus primeros objetivos fue el establecimiento de un centro docente para su disciplina, utilizando las dependencias del Real Gabinete de Máquinas. El Gabinete se vinculó orgánicamente, para ello, a la Inspección (1802), naciendo así los Estudios de la Inspección, que en 1803 pasarían a denominarse Escuela de Caminos y Canales ${ }^{12}$.

11) Ibidem, pp.57.

11 Véase BARREIRO, A. (1932), «El Observatorio Astronómico de Madrid.- Su fundación y desarrollo», Revista de la Academia de Ciencias Exactas, Físico-Químicas y Naturales, t.XXIX, pp.173-190; y Rumeu de Armas, A. (1980), pp.96-98.

12 Véase: Rumeu de ARMAS, A. (1980), pp.93-96; del mismo autor (1980), Ciencia y Tecnología en la España Ilustrada. La Escuela de Caminos y Canales, Ediciones Turner, Madrid; y (1990), El Real 


\section{LUIS ALFREDO BARATAS DÍAZ}

Otro centro significativo en el área estudiada es el Hospital General. Establecido a finales del siglo XVI, en 1748 Fernando VI ordenó la construcción de un nuevo edificio para la institución. La Junta de Hospitales de Madrid encargó (1754) su construcción a Ventura Rodríguez; pero el proyecto de éste fue desestimado por la Junta, encargándose uno nuevo a José de Hermosilla. El proyecto de Hermosilla fue aceptado en 1756, comenzando la construcción en 1758; pero los trabajos se vieron dificultados por la falta de libramientos por parte del Consejo de Castilla, hasta que la utilización de los recursos originados por la expulsión de los jesuitas dio un nuevo impulso a la obra. A la muerte de Hermosilla la construcción se encargó a Sabatini, quién modificó el proyecto de forma considerable. El arquitecto italiano planteó un gigantesco edificio cuadrangular, de 165 metros de fachada por 221 de fondo, con unas charnelas que unían los pabellones independientes diseñados por Hermosilla. Aunque el edificio no llegó a completarse (Mesonero Romanos afirmaba que en 1781 sólo se había finalizado el patio central ${ }^{13}$ ) el proyecto planteaba el establecimiento de un cierto número de elementos secundarios no hospitalarios (iglesia, botica, biblioteca, escuela de cirugía,... etc.), difuminando el carácter estrictamente sanitario del centro, para englobarlo en la política de construcciones civiles y fomento de la actividad científica de Carlos III en Madrid ${ }^{14}$.

Paralelamente al proceso de construcción del edificio del Hospital General, el Duque de Losada, sumiller de corps de Carlos III, realizó en 1776 un informe señalando la necesidad de un colegio de cirugía. Antonio Gimbernat y Mariano Ribas, cirujanos pensionados en Francia y Gran Bretaña, fueron los asesores del proyecto de Colegio de Cirugía de Madrid; a instancias suyas se creó el establecimiento docente en 1787, pero a pesar de sus intenciones el nuevo centro de enseñanza no se instaló en un edificio independiente, sino que lo hizo en el Hospital General, cuyo proyecto, como hemos indicado, contemplaba la existencia de dependencias para enseñanza de la medicina ${ }^{15}$.

Gabinete de Máquinas del Buen Retiro. Origen, fundación y vicisitudes. Una empresa técnica de Agustín de Betancourt, Editorial Castalia, Fundación Juanelo Turriano, Madrid.

1.3 Véase Mesoneros Romanos, R. (1844), Manual histórico-topográfico, administrativo y artístico de Madrid, Imp. Antonio Yenes, Madrid, pp.335.

14 La más completa información sobre el edificio del Hospital General puede verse en: SAMBricio, C. (1982), «El Hospital General de Atocha en Madrid, un gran edificio en busca de autor. Las intervenciones de Ventura Rodríguez, José de Hermosilla y Francisco Sabatini», Arquitectura, n 239, pp.44-52.

15 Véase Usandizaga, M. (1948), Historia del Real Colegio de Cirugía de San Carlos de Madrid (I787-1828), CSIC, Madrid; y Aparicio Simón, J. (1956), Historia del Real Colegio de San Carlos de Madrid, Aguilar, Madrid. Dos obras más recientes son: BURKE, M.E. (1977), The Royal College of San Carlos. Surgery and Spanish Medical Reform in the Late Eighteenth Century, Duke University Press, Durham; y Da Costa Carballo, C.M. (1992) La enseñanza de la medicina a finales del siglo XVIII en las instituciones docentes madrileñas ubicadas en el Hospital General de Madrid, Editorial de la Universidad Complutense, Madrid. 
En conjunto, a finales del siglo XVIII en la confluencia de los Paseos del Prado y de Atoćha había surgido un núcleo importante de edificios de carácter docente e investigador (algunos inacabados y otros completados con éxito) que constituía un digno marco físico para las instituciones y anunciaba una cierta continuidad en el proceso de desarrollo de la actividad científica. Los acontecimientos posteriores (sustitución de Floridablanca, interrupción de la línea reformista ilustrada en la última década del siglo y, sobre todo, la cruenta y devastadora Guerra de la Independencia) frustraron el posible desarrollo institucional y científico.

\section{LA EVOLUCIÓN DE LAS INSTITUCIONES CIENTÍFICAS DEL PRADO-ATOCHA EN EL SIGLO XIX}

Tras el desastre que para los organismos científicos españoles supuso la guerra (ya comentamos que el Observatorio Astronómico y el edificio de la Academia habían sido saqueados, y otro tanto sucedió con los fondos del Real Gabinete de Máquinas), el reinado de Fernando VII no contribuyó a la recuperación de las instituciones científicas. El magno edificio de la Academia de Ciencias se reconvirtió en Museo de Pinturas, las obras de recuperación del Observatorio no se realizaron y las dependencias del Hospital General (pro-yecto inacabado) iban sufriendo un constante y no evitado deterioro.

En uno de esos cortos períodos reformistas que caracterizan la historia del siglo XIX, durante el Trienio Liberal, se plantearon diversos proyectos para dotar al Colegio de Cirugía de un edificio propio. El aceptado finalmente suponía su traslado al convento de San Juan de Dios, pero no llegó a ser efectivo al revocarse la orden de traslado en $1823^{16}$. Posteriormente, en los últimos años del reinado de Fernando VII, la Junta Superior del Colegio solicitó (en 1830) y obtuvo autorización para trasladarse al Hospital de la Pasión y para la construcción de un edificio de nueva planta para el Colegio. El nuevo edificio comenzó a construirse en 1831, instalándose en él los primeros servicios docentes en $1835^{17}$. Fernández de los Ríos, junto algunas ironías sobre la notable capacidad pulmonar que a los profesores exigía el enorme anfiteatro central para 1.300 alumnos, no ahorraba críticas sobre la nueva construcción:

«no fue ciertamente afortunado en la construcción del edificio que para él se levantó. Es la fachada pesada y de mal gusto, sin grandeza y poco adecuada al instituto para que ha sido

\footnotetext{
16 Véase: Fernández de los Ríos, A. (1976), Guía de Madrid. Manual del madrileño y del forastero, Abaco Ediciones, Madrid, pp.531.

17 Véase Aparicio SimÓn, J. (1956), pp.150-154. 


\section{LUIS ALFREDO BARATAS DÍAZ}

erigida; hallase interiormente mal distribuido y se resiente de faltas imperdonables en el pensamiento y la ejecución» 18 .

Diversas obras se acometieron, también, en el Real Jardín Botánico al iniciarse el reinado de Isabel II. Tras un largo período de decadencia entre 1819 y 1827, que había culminado con el traslado de libros y herbarios a los desvanes del Museo del Prado, en 1834 se construyeron dos edificios anejos a la Cátedra, detrás del Pabellón de Invernáculos, con destino a Biblioteca y Herbario y se levantó la estufa de Mediodía o estufa grande ${ }^{19}$.

El balance en la construcción y remodelación de edificios científicos en el área estudiada a lo largo del siglo XIX es, por tanto, bastante pobre. Habría que esperar la llegada de la Restauración para una cierta recuperación de la iniciativa constructora en la zona, si bien se aprecia una diferencia fundamental respecto del proyecto dieciochesco: en éste se desarrolla un ambicioso plan urbanístico y de promoción integral de las instituciones científicas, mientras que en las últimas décadas del siglo pasado las actuaciones oficiales son de carácter puntual, limitándose a la erección aislada de edificios (algunos notables, eso sí) pero sin que exista un proyecto global para la zona.

Además, el establecimiento de la Universidad Central en el Noviciado de los Jesuitas en San Bernardo, en los años cuarenta del siglo XIX, rompió el monopolio que como núcleo docente había alcanzado el área del Prado. El aprovechamiento de los bienes desamortizados a la Iglesia y las dificultades presupuestarias inherentes a todo gran proyecto urbanístico-docente impidieron la constitución de una auténtica 'ciudad universitaria' en la zona. La utilización de una importante porción del terreno adyacente en la construcción de los viales e instalaciones ferroviarias de la línea MadridAranjuez, que andando el tiempo se transformaría en la Estación de Atocha ${ }^{20}$, centro ferroviario de la ciudad, limitó de forma casi definitiva toda posibilidad de expansión de este núcleo científico-docente en los siglos XIX y XX.

Hay que tener en cuenta, además, que ante la falta de suelo edificable (debida al crecimiento de la estación ferroviaria y la creciente presencia de casas de vecindad) el establecimiento de nuevos edificios se hará a costa de los terrenos del Real Jardín Botánico, que verá recortada de forma considerable su extensión.

El primer recorte sobre la superficie del Jardín se realizó para posibilitar la construcción de la Escuela de Artes y Oficios (actual Ministerio de Agricultura). En octu-

18 Cfr. FERNÁNDEZ de los Ríos, A. (1978), pp.532.

19 Véase Bolivar, I. (1930), Jardín Botánico. Estado actual de la enseñanza en España, Blass S. A. Tipografía, Madrid, pp.7-8.

20) Véase López García, M. (1986), MZA. Historia de sus estaciones. Ediciones Turner, Madrid, 1986, pp.57-113. 
bre de 1881 se encargó a Eduardo Saavedra examinar el proyecto de un edificio para Escuela de Artes y Oficios y de Ciencias Naturales (sic) realizado por Lorenzo Alvarez Capra, ordenando su transformación en Facultad de Ciencias ${ }^{21}$. Simultáneamente, el arquitecto Mariano Belmás presentó un proyecto para la construcción de una Escuela de Artes y Oficios ${ }^{22}$. Tras la aprobación por parte del Ministerio de Fomento del proyecto de Belmás, y tras realizarse unas correcciones en los presupuestos, las obras comenzaron en 1882 .

Pero en una decisión súbita e inopinada, una Real Orden de 20 de julio de 1885 informaba al Rector de la Universidad y al Decano de la Facultad de Ciencias que el edificio en construcción pasaba a ser destinado a Facultad de Ciencias y Gabinete de Historia Natural. Posteriormente una Real Orden de 25 de agosto de 1885 reconvirtió la Junta de Obras del edificio y designaba a Saavedra arquitecto en sustitución de Belmás; en octubre la Junta de Obras, a la vista de una petición de la Academia de Ciencias, ordenaba al Arquitecto Saavedra las reformas necesarias para albergar ésta en el edificio en construcción. Finalmente, en una decisión igual de inesperada que la del 20 de julio, un Real Decreto de 17 de diciembre de 1885 establecía:

«Artículo $1^{\circ}$ Se procederá inmediatamente a la construcción de un edificio destinado a Facultad de Ciencias en los terrenos del Jardín Botánico de esta Capital contiguos a los paseos del Prado y Atocha dándose desde luego principio a las obras por administración.

Artículo $2^{\circ}$ Se continuarán con toda la actividad posible para obtener su terminación en breve plazo las obras del edificio que ha de servir de Escuela Central de Artes y Oficios y de Comercio, con arreglo al proyecto que está en ejecución y aprobó aরi mismo aquel Ministerio, quedando en su consecuencia derogada la Real Orden de 20 de Julio último que dispuso la modificación del expresado proyecto para destinar el edificio a Facultad de Ciencias» ${ }^{23}$.

A pesar de la reversión al proyecto original de Escuela de Artes y Oficios, una Real Orden de 4 de febrero de 1886 aprobaba las modificaciones presentadas por Saavedra para el edificio, afirmando que el arquitecto consideraba que éstas eran necesarias fuese cual fuese su destino último. El respeto a las modificaciones planteadas por Saavedra fue seriamente cuestionado por la Real Academia de Bellas

21 Véase la Minuta del Ministerio de Fomento a Eduardo Saavedra, fechada el 26 de octubre de 1881. Archivo General de la Administración, sección de Educación, caja nº 8102, legajo 8874-1. En lo sucesivo AGA, Educación.

22 Véase el Proyecto de Conservatorio de Artes, Escuela de Artes, Oficios y Comercio, 1881. AGA, Educación, caja n n $^{8} 383$.

2.3 Véase el Expediente de obras de construcción de un edificio para Facultad de Ciencias aprovechando las ejecutadas para Escuela Central de Artes y Oficios. AGA, Educación, caja ${ }^{\circ} 8102$, legajo 8874-1. También la Minuta del Director General de Obras Públicas al Ministerio de Fomento, fechada el 18 de diciembre de 1885. AGA, Educación, legajo 5420-67. 
Artes de San Fernando y originó un conflicto de intereses entre el contratista de las obras y el Ministerio de Fomento ${ }^{24}$. Las obras en la Escuela se continuaron hasta 1891, fecha en que el destino del edificio se reconsideró, decidiendo reconvertirlo en sede del Ministerio de Fomento. Las obras para tal fin, que aprovecharon lo ya edificado como Escuela, se encomendaron a Ricardo Velázquez Bosco, quién las acometió a partir de 1893, finalizándolas en 189725 .

El azaroso avatar de este edificio, que fue destinado originalmente a Escuela de Artes y Oficios, en segundo lugar a Facultad, Museo y Academia de Ciencias, nuevamente Escuela de Artes y Oficios, para finalizar siendo sede de un Ministerio, es una prueba de la improvisación de las autoridades educativas de la Restauración, y supone un magnífico ejemplo (trasladado esta vez al marco físico de las instituciones científicas) del constante cambio que las disposiciones educativas (especialmente los planes de estudio) vivieron a lo largo del siglo XIX.

A pesar de todo el edificio de la Escuela de Artes y Oficios, aunque fuese como sede del Ministerio de Fomento, se completó. Peor suerte corrieron diversos proyectos para levantar un edificio destinado a Facultad de Ciencias. Como hemos indicado al estudiar el proyecto de Escuela de Artes y Oficios, en 1881 se planteó un proyecto conjunto de Escuela de Artes y Oficios y Facultad de Ciencias, que Eduardo Saavedra transformó en un proyecto para Facultad de Ciencias en 1882. Dicho proyecto justificaba la utilización de terrenos del Jardín Botánico, aún reconociendo las limitaciones de espacio de éste, por la falta de solares disponibles, y retomando la idea de un «campus universitario» en la zona, señalaba las ventajas que la vecindad con la Facultad de Medicina, el Jardín, el Observatorio Astronómico, el Museo Velasco y la Escuela de Ingenieros de Caminos representaba.

Al considerar la ubicación del edificio señalaba el arquitecto su oposición a situarlo en la esquina superior de la calle Granada (cercano a la esquina de las actuales Alfonso XII y Claudio Moyano), emplazamiento primeramente pensado para la Escuela de Artes y Oficios y la Facultad; proponía, en cambio, el solar inferior situado al hilo del Paseo de Atocha (en el espacio ocupado por el actual Ministerio de Agricultura), con la fachada principal orientada no hacia el Paseo, sino perpendicular a éste, considerando que esta localización y orientación permitiría una entrada meridional digna para el Jardín.

El edificio proyectado comprendía tres plantas (sótano, bajo y principal), distribuidas en torno a dos patios centrales; las fachadas contarían con un zócalo de sillería siendo el resto de la fábrica de ladrillo visto. Un aspecto significativo son las consideraciones que la Memoria explicativa del proyecto incluye acerca de la posibi-

\footnotetext{
24 Véase AGA, Educación, caja nº 8383.

2.5 Véase Anonimo, «El nuevo Ministerio de Fomento», La Ilustración Española y Americana, $\mathrm{n}^{\circ}$ XXXVII, 8 Octubre de 1897, pp.203.
} 
lidad de construir una segunda planta adicional en la que dar cabida a las colecciones del Gabinete de Historia Natural. El proyecto incluye un detallado presupuesto, por un monto de $931.511,15$ pesetas si se ejecuta la versión más sencilla, y de 1.166.493,16 pesetas si se construye la segunda planta para el Gabinete ${ }^{26}$.

El proyecto no se llevaría a término en la localización propuesta por Saavedra, ya que en el solar indicado por éste se iniciaron, como ya hemos visto, las obras de la Escuela de Artes y Oficios. No obstante el proyecto de Saavedra siguió su tramitación administrativa, pasando en enero de 1883 a la Junta Consultiva de Caminos, Canales y Puertos, órgano encargado de examinar las especificaciones técnicas y económicas de los proyectos de obras del Estado. La Junta dictaminó que el proyecto de Facultad de Ciencias presentado por Saavedra podía ser aprobado, pero encomendaba diversas modificaciones de orden técnico y estético (aumento de la altura del sótano, mayores dimensiones en el cuerpo semicircular posterior y entrada mediante una puerta de tres arcos), afirmando, además, que:

«la construcción de un piso más para establecimiento del Museo de Ciencias Naturales, es indispensable, si la Escuela de Ciencias ha de satisfacer cumplidamente todos los fines de su Instituto» ${ }^{27}$.

Recomendaba, también, la Junta Consultiva el mecanismo más adecuado para la realización de las obras (contrata y subasta pública para las obras de movimiento de tierras, fábrica y carpintería, y ejecución directa, o por administración, para los trabajos de decoración y otros menores), encargando en consecuencia ligeras correcciones sobre el presupuesto; éstas fueron presentadas por Saavedra el 5 de junio de 1884, y con fecha 30 de junio se solicitó autorización para convocar la subasta de las obras a contratar. La subasta se anunció el 15 de septiembre de 1884, sin que se presentaran licitaciones, celebrándose una segunda subasta, el 5 de noviembre, con idéntico resultado negativo. Finalmente, a la vista del infructuoso resultado de las subastas, y teniendo en cuenta la necesidad de proporcionar trabajo a la clase obrera madrileña, se ordenó la ejecución de la obra por administración con un presupuesto material de $1.221 .986,47$ pesetas $^{28}$.

Pero la ejecución del proyecto sufrió una brusca alteración, como ya vimos, al dictarse una Real Orden el 20 de julio de 1885 que destinaba el edificio en construc4.

26 El proyecto de la Facultad de Ciencias puede verse en: AGA, Educación, caja 8103 legajo 8874-

27 Cfr. el Informe de la Sección $1^{\text {a }}$ de la Junta Consultiva de Caminos, Canales y Puertos, fechado el 16 de Enero de 1883. AGA, Educación, caja ${ }^{\circ} 8102$, legajo 8874-1.

28 El expediente general de éste proyecto puede verse en: AGA, Educación, caja n $n^{\circ} 8102$, legajo 8874-1. 
ción de la Escuela de Artes y Oficios a Facultad de Ciencias, anulando todas las actuaciones que sobre el proyecto de Saavedra se habían realizado. Finalmente, el Real Decreto de 17 de diciembre restablecía la situación previa al 20 de julio, ordenando la erección de dos edificios independientes, uno para la Escuela de Artes y Oficios y otro destinado a Facultad de Ciencias. De nuevo fue Saavedra el arquitecto encargado de la construcción del edificio de la Facultad, pero el proceso burocrático de la edificación comenzó de nuevo: se designó una nueva representación de la Facultad de Ciencias en la Junta de Obras del edificio y se constituyó un nuevo gabinete de técnicos encargado de la construcción.

Las obras debieron iniciarse de forma casi inmediata, aunque probablemente eran continuación de las ejecutadas sobre el proyecto de 1882. El expediente incluye diversas gestiones para subcontratar el desmonte de los solares y una nota de la Dirección General de Instrucción Pública, fechada el 12 de febrero de 1886, afirma que las obras habían dado comienzo ${ }^{29}$. El edificio en construcción estaba radicado, como indicaba el Real Decreto de 17 de diciembre, entre la Escuela de Artes y Oficios (en construcción) y el Jardín Botánico, en el área que actualmente ocupa la estatua de Claudio Moyano y la zona ajardinada adyacente, con su fachada hacia la plaza formada por la confluencia de los dos paseos ${ }^{30}$.

Pero las modificaciones no se hicieron esperar y una Real Orden de 25 de febrero de 1886 ordenaba variaciones para que el edificio albergase a la Real Academia de Ciencias. También, de nuevo, aparecen la inconstancia y los cam-bios súbitos en las disposiciones administrativas, y sólo dos días después, el 27 de febrero se revocaba la orden dictada el 25.

Además, la ejecución de las obras parece haber tenido serias dificultades en la necesaria canalización de una alcantarilla. El proyecto de alcantarilla fue presentado por Saavedra en abril de 1886; tras el informe de los cuerpos técnicos de la Real Academia de San Fernando, el proyecto sufrió notables modificaciones técnicas, iniciándose las obras en julio de 1886 y finalizándose en febrero de 1887, no formalizándose el acta de recepción de la obra hasta octubre de $1887^{31}$.

29 Ibidem.

30) El plano de la ciudad publicado en 1886 por Benito Martínez y José Méndez, y realizado a lo largo de 1885, incluye el trazado de un edificio en la zona citada, entre el Jardín Botánico y el Ministerio de Fomento, que corresponde sin duda a la Facultad de Ciencias. La fecha de la elaboración del plano nos induce a pensar que algunas obras debían haberse realizado en el solar antes de $1885 \mathrm{y}$, en todo caso, el proyecto debía estar suficientemente avanzado como para que los autores del plano pudiesen conocer su forma y estructura general. Véase VV AA (1979), Cartografía básica de la Ciudad de Madrid. Planos históricos, topográficos y parcelarios de los siglos XVII-XVIII-XIX y XX, Colegio Oficial de Arquitectos de Madrid, Madrid.

31 Véase AGA, Educación, caja nº 8102, legajo 8874-1. 
Paralelamente a la construcción de la alcantarilla, que retrasó las obras ya comenzadas de la Facultad, Saavedra presentó un nuevo proyecto de edificio para la Facultad de Ciencias en 1887. El proyecto no era totalmente nuevo, si no una reinterpretación del proyecto de 1882: se mantenía la forma general del edificio, la distribución en torno a dos patios interiores, la existencia de un segundo piso destinado al Gabinete de Historia Natural, y se introducían las modificaciones propuestas por la Junta Consultiva de Obras Públicas al proyecto de 1882. En la Memoria de este nuevo proyecto Saavedra informa de las dos principales modificaciones:

\footnotetext{
«El primer motivo de variación tiene origen en la necesidad de ampliar el local, correspondiente a las repetidas instancias de los Profesores de la Facultad de Ciencias sobre todo los de la Sección de Historia Natural. Para proceder con acierto el Arquitecto ha conferenciado con la Comisión del claustro nombrada al efecto, ha sometido al examen del claustro mismo varios borradores de extensión y distribución de las plantas y ha procedido con arreglo a sus instrucciones dentro de lo posible.

El otro objeto de la reforma es el aumento de precios. Sacada la obra a subasta, no hubo para ella postor alguno, diciéndose de público que los precios de unidad eran excesivamente bajos, y esto movió al Gobierno a ordenar que se hiciera un nuevo cuadro para intentar nuevamente la subasta» ${ }^{32}$
}

Finalmente, informa el arquitecto de las nuevas dimensiones del edificio (72,60 metros de largo por 60,85 de ancho, lo que rinde un total de 4.421,44 metros cuadrados construidos), estima la duración de las obras en un mínimo de cuatro años y establece el presupuesto total de $2.543 .070,11$ pesetas $^{33}$.

En diciembre de 1887 el proyecto fue remitido a la Academia de Bellas Artes de San Fernando, que lo devolvió en abril de 1888, proponiendo modificaciones en los cálculos de resistencia del edificio, en los planos de la fachada principal y diversas correcciones en las condiciones facultativas y los cálculos presupuestarios (lo que podría explicar las adiciones al presupuesto original). Proponían los informantes de la Real Academia, además, que se consultase la distribución interior de aulas y dependencias con el Director del Museo de Ciencias y el Decano de la Facultad. Las correcciones fueron realizadas por Saavedra, quién sometió de nuevo su proyecto al

32 Cfr. la Memoria del Proyecto para la construcción de una Fàcultad de Ciencias en 1887. AGA, Educación, caja n ${ }^{\circ} 8103$, legajo 8874-3, fols.1-2.

3. Sobre del presupuesto de la edificación hay varias correcciones manuscritas y que no especifican las razones últimas de los cambios. Al presupuesto material para movimientos de tierras y obra, que contaba con una partida de $1.594 .230,95$ pesetas se hace una adición de $328.490,28$ pesetas, y a la partida de Obras especiales y complementarias otra de 150.354 pesetas, lo que eleva el presupuesto de ejecución material a $2.487 .361,03$, y el total a $2.869 .565,24$ pesetas. Véase: Presupuesto del Proyecto para la construcción de una Facultad de Ciencias en 1887. Ibidem. 
dictamen de la Academia en enero de 1889. La Academia dictaminó positivamente las correcciones, devolviendo el proyecto de inmediato, pero la aprobación definitiva de éste se retrasó, sin motivo conocido, hasta agosto de 1889, con un presupuesto de 2.925.576,98 pesetas, pero:

«no se cumplimentó esta orden por haberlo dispuesto así S. E. [el Ministro de Fomento] y por tanto no se mandó el expediente como debía al Consejo de Ministros para su aprobación definitiva» ${ }^{34}$.

El edificio de la Facultad de Ciencias, por tanto, a pesar de haberse ejecutado sus primeras obras fue dejado en suspenso, y las dos versiones del proyecto realizado por Eduardo Saavedra no llegaron a plasmarse en realidad.

Aún existiría un tercer proyecto, también fallido, de Facultad de Ciencias. En agosto de 1893 el arquitecto Velázquez señaló el terreno colindante con la calle Alfonso XII como adecuado para la edificación. A instancias de Miguel Colmeiro, Director del Jardín, se desestimó dicho emplazamiento, que presentaba un muy fuerte desnivel y se optó por construir en:

«el que queda a la izquierda de la nueva calle trazando esta todo lo mas paralelamente a edificios destinados a Ministerio de Fomento, de forma que aquella desembocaría en la puerta de Atocha entre los dos edificios; y adoptando esta solución habría que tomar una nueva parcela del Jardín Botánico, la que fue marcada por el citado Director y comprende desde el sitio en que se empezó a levantar el edificio para la Facultad de Ciencias y la primera Calle del Jardín normal al Paseo de Atocha. Esto obligaría a cortar bastantes árboles pero no tenían importancia alguna según ha manifestado el Sr. Colmeiro.

A juicio del Arquitecto Sr. Velázquez este emplazamiento ofrece grandes ventajas como son la economía en la cimentación y que la entrada de la nueva calle por la Puerta de Atocha con los dos edificios flanqueándola sería desde luego uno de los mejores puntos de Madrid, formando una entrada digna de esta corte» ${ }^{35}$.

El edificio proyectado por Velázquez suponía una construcción de 95 por 45 metros, con una superficie total de 4.275 metros cuadrados. La última referencia encontrada sobre este proyecto ordena a Velázquez la redacción del proyecto completo (memoria, planos, presupuesto,...etc.) teniendo en cuenta los proyectos anteriores diseñados por Saavedra. Una revisión general del expediente de construcción realizada por el Negociado de Construcciones Civiles del Ministerio de Fomento, firmada

\footnotetext{
34 Cfr:: Expediente del Negociado de Construcciones Civiles del Ministerio de Fomento, relativo a la construcción de la Facultad de Ciencias. AGA, Educación, caja 8102, legajo 8874-1.

35 Ibidem.
} 
en 1898, afirma que Velázquez no realizó el encargo y ante una exposición del Rector de la Universidad de Madrid, insistiendo en la necesidad del edificio, recomienda que se encarezca al arquitecto la urgente realización del proyecto ${ }^{36}$. Aunque el expediente citado parece acusar a Velázquez de negligencia, y a pesar de no existir más documentación sobre este tercer proyecto, nos inclinamos a pensar que su realización fue totalmente desestimada entre 1894 y 1895 cuando se trazó la calle Claudio Moyano, que determinó la separación de dos parcelas en el Jardín Botánico: una situada sobre el Paseo del Prado, que comprendía la zona ajardinada y es el recinto actual de la institución, y otra que dio lugar a la manzana ocupada por el Ministerio de Fomento y la zona ajardinada aneja ${ }^{37}$.

En todo caso, la construcción de un edificio sede de la Facultad de Ciencias se abandonó definitivamente, y no se contaría con locales propios y dignos para la enseñanza universitaria de las ciencias en Madrid hasta entrado el siglo XX, cuando las obras de la Ciudad Universitaria plantearon la construcción de un conjunto de edificios para tal fin, pero ya fuera del ámbito de los paseos de Atocha y del Prado.

La inexistencia de proyectos para la construcción de un edificio de Facultad de Ciencias hasta bien entrado el siglo XX, no debe inducir a pensar que los profesores e investigadores vinculados a la Universidad de Madrid no realizaron peticiones en tal sentido. En febrero de 1898, los integrantes del claustro de la Facultad de Ciencias elevaron un informe sobre «Principales datos que deben tenerse presentes para la construcción de un edificio destinado a Facultad de Ciencias y Museo de Ciencias naturales» que constituye un detallado examen de las condiciones en las que se impartía la enseñanza científica a finales del siglo XIX y una relación de propuestas y características técnicas que debe presentar el nuevo e imprescindible edificio. Comentaban los profesores que una de las dificultades más graves que afrontaba la actividad docente de la Facultad era la dispersión de los edificios: las clases se impartían en la sede central de la Universidad en San Bernardo, otras en el Instituto de San Isidro, otras en el Museo (radicado ya en el edificio de la Biblioteca Nacional) o en el Jardín Botánico; afirmando además que «las circunstancias y condiciones relativas a los locales destinados a cátedras y laboratorios son extremadamente deplorables», aspecto que redundaba sobre la calidad de la enseñanza, que:

«tiene que quedar reducida a explicaciones orales, que si son suficientes en las ciencias especulativas a condición sin embargo de quedar el Profesor a disposición del alumno para aclarar las dudas que a este le puedan ocurrir, distan mucho de lo necesario en las ciencias

\footnotetext{
36 Ibidem.

37 Véase: Expediente relativo a las obras de cerramiento con verja del Jardín Botánico de esta Corte por la nueva calle del Angel Caído y la de Alfonso XII. AGA, Educación, caja n ${ }^{\circ}$ 8103, legajo 8875-1 y proyecto de cerramiento del Jardín Botánico, 1895. AGA, Eduación, caja nº 8109, legajo 8878-7.
} 
experimentales, de observación y aplicación, pues las más luminosas descripciones no pueden reemplazar nunca al experimento, al exámen de los objetos, o al ejercicio práctico» ${ }^{38}$.

Se manifestaba el Claustro, en consecuencia, a favor de la construcción de un edificio para la Facultad de Ciencias y Museo de Ciencias Naturales y, siguiendo la línea de los diversos proyectos planteados durante la Restauración, propugnaba su erección en terrenos del Jardín Botánico, en la zona colindante con la calle Claudio Moyano. Esta propuesta, que hubiera alterado considerablemente al Jardín, afectando incluso la porción ajardinada limítrofe con el Paseo del Prado, no alcanzó mayor repercusión.

Incluía, además, la Memoria del Claustro de la Facultad un apéndice en el cual se detallaban las características del futuro edificio: su carácter mixto Facultad-Museo, la existencia de cuatro plantas (sótano, principal, primera y segunda) y las dimensiones, orientación y condiciones de todas las dependencias docentes e investigadoras ${ }^{39}$. El informe del Claustro y su apéndice son una prueba excelente del profundo conocimiento entre los profesores de Ciencias de la época de las necesidades institucionales de sus disciplinas y, al tiempo, suponen una valoración positiva de los proyectos fracasados presentados por Saavedra en la década de los ochenta, ya que éstos presentan la misma estructura general que el edificio solicitado por los universitarios.

En cualquier caso el edificio solicitado por los profesores no llegó a alcanzar más relevancia oficial. Cabe recordar que la propuesta se realizó en una época turbulenta ( en 1898 se desarrollaba la guerra contra los independentistas cubanos y los Estados Unidos); pero en una etapa posterior, a partir de 1900, cuando la creación del Ministerio de Instrucción Pública inauguró una política reformista que afectó a la estructura docente y organizativa de la Facultad de Ciencias y del Museo de Ciencias Naturales no tenemos constancia de proyectos para construir un nuevo edificio de la Facul$\operatorname{tad}^{40}$.

\footnotetext{
38 Véase: Memoria del Claustro de la Facultad de Ciencias, fechada el 25 de febrero de 1898. AGA, Educación, caja nº 8102, legajo 8874-1.

39 Ibidem.

40) Véase Baratas díaz, L.A. y Fernández Pérez, J. (1992), «La enseñanza universitaria de las Ciencias Naturales durante la Restauración y su reforma en los primeros años del siglo XX», Llull, vol $15, \mathrm{n}^{\circ} 28$, pp.7-34. Sólo hemos encontrado una muy vaga información de un proyecto de edificio a construir en terrenos del Jardín Botánico en 1912. En un informe de noviembre de ese año sobre una obra de importancia menor, la Junta Facultativa de Construcciones Civiles dice: «Como esta instalación se proyecta en la parte del Jardín Botánico, en la que se trata de establecer un edificio para la Facultad de Ciencias, sería conveniente tener presente la instalación probable de este edificio, para no producir gastos en obras de corta existencia». Esta imprecisa mención y la ausencia de información más detallada, nos hace pensar que el supuesto edificio era más una mera intención que un proyecto formal. Informe de
} 


\section{EL NÚCLEO DE INSTITUCIONES CIENTÍFICAS MATRITENSES EN EL PASEO DEL PRADO}

El resultado final de esta larga serie de propuestas y proyectos frustrados fue la utilización de terrenos del Jardín Botánico para dependencias administrativas o viarias, pero no para edificios de interés científico o académico, y la carencia de una institución universitaria bien dotada en la que desarrollar las actividades docentes y científicas inherentes a la Facultad de Ciencias.

Una pequeña institución científica establecida en el área estudiada a finales del siglo XIX fue el Museo Antropológico o Museo Velasco. Pedro González de Velasco era un notable anatomista y cirujano, que había obtenido, gracias al ejercicio profesional, cierta fortuna; también había reunido a lo largo de su vida una notable colección de preparaciones de anatomía humana, de anatomía comparada y de objetos histórico naturales y antropológicos ${ }^{41}$. A principios de 1873 González de Velasco adquirió un solar en la esquina del Paseo de Atocha y Calle Granada (actual Alfonso XII), con la pretensión de levantar un edificio que albergase su colección científica. El arquitecto Francisco de Cubas diseñó un cuerpo central destinado a área de exposición, al que se adosaban dos alas laterales, en las que tendrían cabida la vivienda del Doctor y diversas salas de trabajo y estudio. Las obras comenzaron en abril de 1873 y dos años después, en abril de 1875, se inauguraba oficialmente el Museo. Las obras tuvieron un coste elevadísimo y condujeron a la ruina económica del Doctor ${ }^{42}$. Tras su muerte el edificio y las colecciones fueron adquiridos por el Estado pasando a constituir la Sección Antropológica del Museo Nacional de Ciencias Naturales ${ }^{43}$ y, como veremos más adelante, en el siglo XX alojó importantes laboratorios de investigación biológica.

\footnotetext{
la Junta Facultativa de Construcciones Civiles, fechado el 22 de noviembre de 1912. AGA, Educación, caja $n^{\circ} 5412$, legajo $13616-2$

41 Véase una aproximación biográfica en: LÓPEZ PIÑERO, J.Ma (1983), «Pedro González de Velasco», en Diccionario histórico de la ciencia moderna en España, Ed. Península, Barcelona, 2 vols., vol.I, pp.417-420. Un panorama general de la Antropología del XIX y del Museo Velasco puede verse en: Puig SAMPER, M.A. y Galera, A. (1983), La Antropología española del siglo XIX, CSIC, Cuadernos Galileo de Historia de la Ciencia, Madrid, 1983. La descripción de los fondos de la colección puede verse en: Pulido, A. (1876), Reseña del Museo Antropológico del Doctor Velasco (sito en el Paseo de Atocha de esta Capital), Imp. Julián Peña, Madrid.

42 Véase Sierra DelaGe, M. (1982), «El Museo del Doctor Velasco. Proyecto del Marqués de Cubas», Goya. Revista de Arte, no 167-168, pp.287-294.

4. Véase Romero DE TEJADA, P. (1977), «La Antropología española y el Museo Nacional de Etnología (1875-1974)», en M. Rivera Dorado (ed.), Antropología de España y América, Editorial Dosbe, Madrid, pp.295-297.
} 
EL JARDÍN BOTÁNICO, EL MUSEO ANTROPOLÓGICO Y EL INSTITUTO CAJAL: ÚLTIMAS OBRAS DE RELEVANCIA CIENTÍFICA EN EL ÁREA DEL PRADO-ATOCHA EN LAS TRES PRIMERAS DÉCADAS DEL SIGLO XX.

El terreno ocupado por el Real Jardín Botánico sufrió a lo largo de la Restauración, como hemos visto, diversos recortes que lo redujeron a su extensión actual. Hay que señalar, también, que durante el siglo XIX no se habían realizado en él obras de relevancia, limitándose la actividad a reparaciones, nuevos cerramientos y obras de conservación ${ }^{44}$.

En los primeros años del siglo XX, a pesar de la política de reformas desarrollada por el Ministerio de Instrucción Pública, el Jardín no mejoró sus instalaciones de forma apreciable; incluso hubo de hacer frente a la pretensión de convertir uno de las alas del Pabellón Villanueva en aula de pintura del paisaje de la Escuela de Pintura, Escultura y Grabado ${ }^{45}$. Posteriormente, en febrero de 1905 , en respuesta a un requerimiento cursado por el Ministerio de Instrucción Pública sobre las mejoras a realizar en edificios públicos, el Director del Jardín solicitaba la «construcción de un pabellón para trabajos de Fisiología vegetal adosado en la parte opuesta y simétrica con el de Histología vegetal, aprobado el año pasado este último y todavía no construido» ${ }^{46}$ y otras obras menores (instalación de bocas de riego, pintado de la verja o construcción de una garita para el vigilante). Tras la preceptiva visita de inspección, el arquitecto Enrique Jort remitió, en septiembre de 1905, un presupuesto que sólo consideraba el pintado de la verja. En enero de 1906 Jort enviaba al Negociado de Construcciones Civiles del Ministerio el proyecto y presupuesto de las restantes obras solicitadas. Tras el informe positivo de la Junta de Construcciones, una nota del Negociado de marzo de 1906 proponía la ejecución de las obras; pero la obra de más trascendencia (el pabellón de Fisiología Vegetal) no se ejecutó, sufriendo además el proyecto una modificación por parte de otro arquitecto, y una nota del Negociado de

44 Existe documentación sobre obras en el Real Jardín Botánico de Madrid a lo largo del siglo XIX en el Archivo General de la Administración, Sección de Educación, que comprende información sobre obras de cerramiento (cajas $n^{\circ} 8103$, legajo 8875-1, y $n^{\circ} 8109$, legajo 8878-7), remodelaciones y obras de consolidación de las estufas (cajas $n^{\circ} 8105$, legajos 8876-4 y 8876-10, y caja n ${ }^{\circ} 8109$, legajo 8878-6), y obras de acondicionamiento para la exposición de objetos de la Expedición al Pacífico (caja $n^{\circ} 8109$, legajo 8878-3).

4.5 Véase: Proyecto de reforma de parte de la estufa para instalación de clase de pintura del paisaje, fechada el 24 de octubre de 1901. AGA, Educación, caja nº 8370, legajo 9068-12.

46 Véase: Minuta del Negociado de Construcciones Civiles, fechada el 23 de febrero de 1905. AGA, Educación, caja nº 5412, egajo 13616-2. 
Contabilidad del Ministerio detenía su ejecución por «estar acabada y sobrepasada la partida de Conservación y reparación de establecimientos» ${ }^{47}$.

No hay más información de obras de relevancia en el seno del Jardín hasta 1917, cuando el Director comunicó «la necesidad de llevar a efecto reparaciones urgentes en alguno de los Pabellones y también la ampliación de estos en orden a las necesidades de la enseñanza, para poder adaptarlos a las Cátedras y Laboratorios de Fisiología Vegetal» ${ }^{48}$. Ante esta petición se autorizó (en junio de 1917) al arquitecto Enrique Repullés a realizar un proyecto detallado de las obras, que éste presentó en noviembre. El proyecto suponía la ampliación de un piso sobre la antigua estufa (conocida como pabellón Villanueva), y contaba con un presupuesto de ejecución por contrata de 152.142,29 ptas. Este proyecto fue remitido a la Junta de Construcciones Civiles, que cuestionó seriamente su validez estética y técnica:

\footnotetext{
«la Junta tiene la honra de informar a V.I., la conveniencia de desistir de la obra de elevación de un piso en la estufa del Jardín Botánico; en caso de no aceptarse esa solución la conveniencia de devolver el proyecto estudiado a su autor con el cuidado de dejar al edificio resultante con un aspecto digno del Jardín en que está implantado; y si las dos proposiciones anteriores no fuesen admitidas por V.I. que pueden aprobarse el Presupuesto y el Pliego de condiciones consignando en ellas que ha de regir también el Reglamento de Construcciones Civiles de 4 de Septiembre de $1908 »^{49}$.
}

Finalmente, aunque una nota manuscrita del expediente afirma que el proyecto no se ejecutó por fallecimiento del arquitecto, parece razonable que el duro informe negativo de la Junta Consultiva determinase su abandono.

Hay que considerar, además, que las obras de reforma en el Jardín Botánico debieron verse dificultadas gravemente por el enfrentamiento mantenido por su dirección con la Junta para la Ampliación de Estudios, organismo ministerial del que dependía el Jardín ${ }^{50}$. La llegada de Ignacio Bolívar a la Dirección del Jardín y la renovación institucional subsiguiente se tradujo en el desarrollo de una serie de mejoras en las dependencias del Jardín. En 1920, ya se habían planteado y realizado diversas reparaciones de importancia en el Jardín (refor-mas en las estufas, consolidación de muros, obras de alcantarillado,... etc.); pero sería a partir 1921, con Bolívar como

\footnotetext{
47 Véase: Minuta del Negociado de Construcciones Civiles, fechada el 18 de julio de 1907. Ibidem.

48 Cfr.: Minuta del Director del Jardín Botánico, fechada el 17 de abril de 1917. Ibidem.

49 Cfr:: Informe de la Junta Consultiva de Construcciones Civiles, fechado el 12 de diciembre de 1917. Ibidem.

50 Véase: GonZÁlez Bueno, A. y Gallardo, T. (1988), «Los estudios botánicos en la Junta para la Ampliación de Estudios», en J.M. Sánchez Ron (ed.), 1907-1987. La Junta para la Ampliación de Estudios e Investigaciones Científicas 80 años después, CSIC, Madrid, t.II. pp.466-470.
} 


\section{LUIS ALFREDO BARATAS DÍAZ}

Director, cuando se afrontase, de nuevo, la construcción de Laboratorios para el Jardín.

En diciembre de 1921 el arquitecto Pedro Muguruza presentó un proyecto para la instalación de nuevos laboratorios en el Jardín, retomando la idea de erigirlos sobre la antigua estufa (Pabellón Villanueva), levantando las cubiertas de la zona central y cerrando con forjado metálico y fabrica de ladrillo una nave con ventanales en la que se dispondrían mesas de trabajo y armarios para material de investigación, comunicando con el vestíbulo del piso inferior mediante una escalera de caracol. El proyecto fue informado por la Junta Consultiva de Construcciones Civiles del Ministerio que desaconsejaba la obra, pero no mostraba una total oposición a ella:

\footnotetext{
«Ha sido idea constante de la Dirección del Jardín Botánico la ampliación del Herbario o antigua estufa para la instalación de una u otras dependencias. Ya en el año 1917 fue examinado por la Junta un proyecto según el cual se aumentaba un piso en toda la extensión del herbario y el trazado entonces propuesto destruía por completo el aspecto y carácter del actual cuerpo del edifico al punto que no pareció aceptable, ante la consideración del daño que con ello se causaba a una construcción sencilla en su conjunto, de elegante forma y correcto dibujo.

Alterados resultan también el conjunto y el aspecto del Herbario con la reforma que ahora se propone; no se infiere, sin embargo, tan grave quebranto al carácter del edificio como en aquella otra de 1917.

Por esto cree la Junta que sería siempre preferible dedicar alguna superficie del Jardín a la construcción de un pabellón especial para el servicio de que se trata. Pero si V.I. tiene conocimiento de que sea realmente imposible disponer de terreno para el destino indicado, puede aprobar el proyecto examinado, que está debidamente formulado y ofrece una solución económica, siendo procedente, en este caso, que la obra se ejecute por administración y por su expresado presupuesto de veinte mil quinientas noventa y cuatro pesetas y cuarenta y dos céntimos» ${ }^{51}$.
}

Finalmente, aunque una nota del Negociado de septiembre de 1922 proponía la ejecución de la obra, y esta contó con el visto bueno ministerial, una nota manuscrita del expediente nos informa lacónicamente que: «No tuvo efecto el presente acuerdo». Paralelamente presentó Muguruza, en abril de 1922, una segunda fase de la construcción de laboratorios sobre el Pabellón Villanueva, por un importe de 25.000 pesetas, que siendo aprobado por la Junta Facultativa de Construcciones Civiles, obtuvo el visto bueno del negociado y del Ministerio en enero de 1924. Pero una nota del Negociado de abril de 1924 afirmaba:

51 Cfr.: Informe de la Junta Consultiva de Construcciones Civiles de 26 de febrero de 1922. AGA, Educación, caja $n^{\circ}$ 5412, legajo 13616-2. 
«resultando que por la carencia de crédito en la consignación destinada a esta clase de atenciones dentro del correspondiente presupuesto, no pudo acordarse el libramiento de la expresada cifra, no pudo, por tanto, llevarse a cabo las citadas



Ante este situación, el proyecto de construcción de una segunda planta para laboratorios debió ser desestimada, y las obras en el Jardín reconducidas hacia la reparación y reforma de los edificios ya existentes; en julio de 1924 remitió Muguruza al Negociado tres proyecto relativos al "primer grupo de obras de reparación en el Pabellón del Laboratorio". De los informes de la Junta Consultiva de Construcciones Civiles se deduce que estas obras eran de reparaciones interiores y exteriores en la estufa o Pabellón Villanueva, y no incluían obras tendentes a levantar un nuevo local para los laboratorios. El primer de los tres proyectos sería aceptado por el Ministerio y ejecutado antes del final de 1924, mientras los otros dos proyectos serían aprobados oficialmente en febrero de $1927^{53}$.

No hay documentación que explique, más allá de las sempiternas dificultades económicas, la falta de ejecución de obras en el piso alto del Pabellón Villanueva. Teniendo en cuenta las dificultades surgidas entre las autoridades educativas y la Junta para la Ampliación de Estudios en los primeros años de la Dictadura de Primo de Rivera ${ }^{54}$, parece razonable pensar que el Ministerio presentase oposición a obras de nueva planta desarrolladas por la Junta, pero encontrase más difícil justificación para no llevar a término obras de reacondicionamiento. La mejora de las relaciones entre la Junta y el Directorio con el transcurso del tiempo, permitiría que en 1927 se reactivase el programa de mejoras en el Jardín, aprobándose los dos proyectos planteados en julio de 1924, remodelándose la estufa del jardinillo (con un presupuesto de $43.259,79$ pesetas) y la presentación, de nuevo, del proyecto de laboratorios sobre el Pabellón Villanueva, esta vez como sede de la Cátedra de Microbiografía (sic) e Histología, sobre el que a pesar de ser favorablemente informado por la Junta Consultiva de Construcciones Civiles (en agosto de 1827) no hubo resolución ministerial $^{55}$. Pese a todo, este nuevo piso debió empezar a construirse, ya que en diciembre de 1930 el arquitecto Muguruza presentó un proyecto de ampliación de obra, que fue examinado por la Junta consultiva de construcciones civiles, que afirmaba:

\footnotetext{
52 Cfr.: Nota del Negociado de Construcciones Civiles fechada el 28 de abril de 1924. Ibidem.

53 Véase: Nota del Negociado de Construcciones Civiles, fechada el 21 de febrero de 1907. Ibidem.

54 Véase: LAPORTA, F. et al. (1987), «Los orígenes culturales de la Junta para la Ampliación de Estudios», Arbor, t.127. n 499, julio-agosto, pp.68-73.

55 Véase: AGA, Educación, caja n ${ }^{\circ} 5412$, legajo 13616-2. El proyecto puede verse en AGA, Educación, caja n ${ }^{\circ} 5335$, legajo 13552-20.
} 


\title{
LUIS ALFREDO BARATAS DÍAZ
}

\begin{abstract}
«Una de las más interesantes de estas reformas se empezó a realizar en el pabellón de laboratorios, levantando una planta sobre la existente, operación que se ha venido ejecutando por tramos.

El proyecto de obras de ampliación que ha presentado actualmente el Arquitecto Sr. Muguruza /.../ propone la continuación de esta parte de la total reforma, interrumpida durante años por la necesidad de atender con urgencia a otros servicios y comprende la porción de laboratorios correspondientes a tres intercolumnios de la fachada principal, en una línea de once metros» ${ }^{56}$.
\end{abstract}

Por tanto, la construcción de laboratorios sobre el Pabellón Villanueva se iniciaría en los últimos años de la década de los veinte ${ }^{57}$, pero su desarrollo se supeditaría a la ejecución de imprescindibles obras de reparación y mejora en éste (pavimentación y mobiliario, arreglo general de la cátedra de Botánica), enlucido de las fachadas de las antiguas aulas y archivo (el edificio localizado tras el Pabellón Villanueva), reparaciones globales en las estufas, pavimentación de paseos y reparaciones en los andenes de piedra que delimitaban los tres bancales del Jardín, realizadas entre 1928 y $1930^{58}$.

A principios de 1931 se retomaría la construcción de laboratorios sobre el pabellón Villanueva, dando el Negociado de Construcciones Civiles el visto bueno a la obra y presupuestando para su ejecución $44.389,64$ ptas. En los meses siguientes se presentarían y aprobarían nuevos proyectos parciales para la continuación de las obras en el piso alto del Pabellón (noviembre de 1932, febrero de 1933, diciembre de 1933) y no se abandonarían las obras en las estufas y la mejora de la zona ajardinada.

Finalmente, tras la práctica suspensión de obras durante el bieno cedista (19341935) el ritmo de las obras se recuperó en 1936 cuando Manuel Sánchez Arcas, nuevo arquitecto director de obras en el Jardín, presentó un proyecto para completar unas obras inacabadas en el piso alto del Pabellón ${ }^{59}$; el estallido de la guerra civil en julio de 1936 impidió, con toda probabilidad, el desarrollo de la obra y supuso el punto final a un programa de mejora en los edificios del Jardín Botánico.

Otra institución con intensa actividad en el primer tercio del siglo XX fue el Museo Antropológico. Como ya indicamos al tratar las instituciones de la zona en el siglo XIX, el Estado se había hecho cargo de ésta a la muerte de Pedro González de

56 Cfr.: Informe de la Junta Facultativa de Construcciones Civiles, fechado el 9 de diciembre de 1930. AGA, Educación, caja nº 5412, legajo 13616-2.

57 La pequeña obra de Ignacio Bolívar sobre el Jardín Botánico publicada en 1930, incluye algunas fotos en las que se ve el Pabellón Villanueva y los laboratorios construidos sobre él, demostrandose, por tanto, que la obra se realizó antes de esa fecha. Véase Bolivar, I. (1930).

58 Véase ibidem y AGA, Educación, caja n 5342 , legajo 13557-8.

59 Véase: Informe de la Junta Facultativa de Construcciones Civiles, fechado el 28-4-1936. AGA, Educación, caja n 5412 , legajo 13616-2. 
Velasco (1882). En los últimos años del siglo pasado no se realizaron obras de entidad en el Museo, limitándose a pequeñas obras de reparación y construcción de mobiliario; cabe citar, no obstante, que las obras de reparación se justificaban por la escasa capacidad de sufrimiento del material, lo que mueve a considerarlo como de mala calidad y parece anunciar los graves problemas que a lo largo del siglo XX afectaron al edificio ${ }^{60}$.

No tenemos constancia de obras a lo largo de la primera década del siglo XX en el Museo, pero la instalación en él del Laboratorio de Investigaciones Biológicas, dirigido por Santiago Ramón y Cajal (en 1900-1901) ${ }^{61}$, debió dar lugar a pequeñas obras de acondicionamiento. Las primeras obras de entidad de las que tenemos noticia se iniciaron en 1912, con motivo de los desperfectos causados por unas lluvias torrenciales. Esta obra inauguró una larga serie de reparaciones en las cubiertas, que se complicaría, además, con la aparición de filtraciones de humedad desde el subsuelo (véase Tabla II). Diversos informes nos muestran al edificio en un estado deplorable; así un informe de la Junta Facultativa de Construcciones Civiles reconocía que el arquitecto encargado de las obras había encontrado «en una cuarta parte del área de la sala los maderos de pino podridos y acometidos de gran humedad, pudiendo asegurar que se halla en estado de ruina inminente» ${ }^{62}$, y otro de 1919 afirmaba que:

\footnotetext{
«En la Memoria se denuncia el mal estado en que se encuentra la habitación del Conserje por las grandes y nauseabundas humedades que sufren el suelo y las paredes a consecuencia del completo deterioro de una atarjea que atraviesa por debajo y que es preciso reconstruir, rehaciendo también la cocina, poniendo nuevo pavimento y ejecutando las obras consiguientes de parcheo, guarnecido y blanqueo de los mismos.

Se denuncia además el peligro que ofrecen las cubiertas de la sala grande, por haberse producido fuertes filtraciones que han abolsado el cielo raso con desprendimiento de algunos trozos del revestido» ${ }^{63}$.
}

Obras de tal entidad necesariamente debieron dificultar enormemente el desarrollo de la actividad docente e investigadora del centro; no obstante, la ausencia de grandes y modernas dependencias académicas, forzaban a la utilización de los edificios existentes fuera cual fuese su estado: en 1915 se solicitó la realización de obras para el acondicionamiento de un laboratorio de Análisis Químico, dependiente de la

\footnotetext{
60) Véase: AGA, Educación, caja nº 8197, legajo 8937-2.

61 Véase RAMÓN y CAJAL, S. (1917), Recuerdos de mi vida. Historia de mi labor científica, Imp. Nicolás Moya, Madrid, pp.400.

${ }_{62}$ Cfr.: Informe de la Junta Facultativa de Construcciones Civiles, con fecha 11 de noviembre de 1914. AGA, Educación, caja n ${ }^{\circ} 4959$, legajo 13276-3. Ibidem.

6.3 Cfr.: Informe de la Junta Facultativa de Construcciones Civiles, fechado el 19 de febrero de 1919.
} 
cátedra homónima de la Facultad de Ciencias, proyecto que se aprobó y ejecutó a lo largo de $1916^{64}$.

Las condiciones del edificio, a pesar de las obras de reparación en los tejados, fueron degradándose poco a poco, y en los años treinta el edificio precisaba ya una profundísima reforma. A finales de 1932 los locales utilizados por la cátedra de Análisis Químico fueron cedidos a la Junta para la Ampliación de Estudios, y en los primeros meses de 1933 se pretendió establecer en ellos un Laboratorio de Paleontología, proyecto del arquitecto Javier de Luque. El análisis que la Junta Facultativa de Construcciones Civiles hace de dicho proyecto reconoce la existencia de un grave deterioro en el edificio y la necesidad de reformas estructurales profundas:

«Consigna la Memoria que ya en el piso primero fue anteriormente instalado un laboratorio de Química, que fue preciso abandonar por los trastornos debidos a descensos de dicho relleno y a fugas de agua que produjeron grietas y bombeos en algunas fábricas que presentan aspecto ruinoso, y que será necesario consolidar ahora y recalzar los muros para evitar la repetición del daño.

Las obras que la realización del proyecto requiere son, vaciado de escombros, recalzo de cimientos, apertura de huecos en fachada, construcción de tabiques de distribución y de un piso de viguería metálica con forjado de bovedilla, pavimentación de baldosín, instalación de retretes y de las conducciones de los servicios de agua y luz, mas las complementarias de pintura, vidriería, etc. El suelo se saneará con gruesa capa de hormigón ${ }^{65}$.

Posteriormente, en noviembre de 1933 la dirección del Museo solicitó la cesión del piso segundo del mismo, que había sido utilizado por el Laboratorio de Investigaciones Biológicas y la verificación de obras en el mismo, en consonancia con el proyecto anterior. El Comité de Patronato de los Museos Nacional de Ciencias Naturales, Antropológico y Jardín Botánico hizo una valoración muy negativa del proyecto e insistió en el mal estado del edificio, recomendando que el Arquitecto del Ministerio de Instrucción realizase una visita de inspección y presentase un proyecto global de reparación ${ }^{66}$. Siguiendo este consejo se cursó la orden a Manuel Sánchez Arcas, el 13 de diciembre de 1933, pero nada se ejecutó, y a lo largo de 1935 diversas minutas ministeriales recordarían a Sánchez Arcas la instrucción dada, sin resultado alguno. El posterior estallido de la Guerra Civil paralizó toda posible obra en el Museo y no sería hasta 1943, cuando se iniciase la reforma del edifício.

\footnotetext{
64 Véase el expediente de obras en el Museo Antropológico entre 1912 y 1935. AGA, Educación, caja $n^{\circ} 5408$, legajo 13613-1. Ibidem.

6.5 Cfr.: Informe de la Junta Facultativa de Construcciones Civiles, fechado el 22 de mayo de 1933.

ar Informe del Patronato de Museos Nacional de Ciencias Naturales, Antropológico y Jardín Botánico, fechado el 2 de diciembre de 1933. Ibidem.
} 


\section{EL NÚCLEO DE INSTITUCIONES CIENTÍFICAS MATRITENSES EN EL PASEO DEL PRADO}

La última gran institución científica construida en el área del Paseo del Prado y de Atocha fue el Instituto Cajal. El Instituto se creó mediante un Real Decreto de 20 de febrero de $1920^{67}$, e inmediatamente se planteó la construcción de un edificio ${ }^{68}$ de nueva planta como sede para la institución, superando la pequeñez y falta de condiciones del laboratorio instalado en el Museo Antropológico. Hasta 1921 no se dispuso de presupuesto para adquirir el solar, pero previamente se habían establecido contactos con la Casa Real, propietaria de los terrenos del Cerro de San Blas y finalmente, una Real Orden de 10 de febrero de 1921 autorizaba la compra de los solares. La realización del proyecto empezó de forma inmediata: el 27 de febrero una minuta del vicepresidente de la Junta, Ignacio Bolívar, al Ministerio de Instrucción informaba que el anteproyecto del edificio ${ }^{69}$ planteaba la construcción de dos pabellones, el primero de los cuales había sido encomendado al arquitecto Javier de Luque; postergando hasta su finalización la construcción del segundo.

El edificio proyectado estaba destinado, en principio, a Laboratorio de fisiología humana y era de planta rectangular, con tres alturas más un semisótano y con la fachada principal orientada hacia el sur, presupuestándose en $489.393,10$ pesetas $^{70}$. Sometido a examen de la Junta Facultativa de Construcción Civiles, ésta dictaminó que el proyecto era técnicamente aceptable pero aconsejó modificaciones de orden estético en el diseño de las fachadas. Aceptado el informe por el Negociado de Construcciones Civiles y el Ministerio de Instrucción a finales de marzo de 1921, la orden de modificaciones en las fachadas se transmitió a Luque en enero de 1922. En febrero, realizadas las correcciones, se solicitaba y obtenía permiso para iniciar las obras de explanación y cimentación, que se realizarían en cuatro fases, con un presupuesto total de $99.258,32$ pesetas.

Desgraciadamente, en junio de 1922 el proyecto de construcción del Instituto Cajal se vería seriamente alterado y se iniciaría un largo proceso de edificación, con resultados no totalmente óptimos. El 8 de junio de ese año la Junta de Construcciones Civiles informaba al Subsecretario de Instrucción Pública de la presentación de

67 Véase: Real Decreto de 20 de febrero de 1920 creando un Instituto para Investigaciones Biológicas que llevará el nombre de Instituto Cajal. Reproducido en: Colección Legislativa de Instrucción Pública. Año de 1920, Talleres del Instituto Geográfico y Estadístico, Madrid, 1921, pp.111.

68 En una carta a Pío del Río Hortega fechada en febrero de 1920, ofrece Ramón y Cajal acomodo al Laboratorio de Histopatología en el «Instituto Biológico edificable en el cerro de San Blas». Véase Río ORTEGA, P. (1986), El Maestro y yo, CSIC, Madrid, pp.88.

69) Según afirma Bolívar este anteproyecto estaba desarrollado por «biólogos conocedores de los Institutos similares extranjeros» a los que no cita. Gonzalo Rodríguez Lafora menciona como asesores científicos del proyecto a Juan Negrín y Francisco Tello. Véase RodríGuEZ LAFORA, G. (1931), «El Instituto Cajal no se acaba de construir», Crisol, 29 de Diciembre, pp.8.

70) Véase: Informe de la Junta Facultativa de Construcciones Civiles, fechado el 15 de marzo de 1921. AGA, Educación, caja n ${ }^{\circ}$ 5404, legajo 13609-6. 


\section{LUIS ALFREDO BARATAS DÍAZ}

un nuevo proyecto para el Instituto Cajal, que suponía el abandono de la construcción de dos pabellones, fundiendo en un solo cuerpo la totalidad de las dependencias. El informe de la Junta de Construcciones Civiles afirma que la decisión de realizar un sólo edificio fue tomada conjuntamente por el arquitecto y por Ramón y Cajal. El nuevo edificio aprovecharía las obras de explanación y cimentación realizadas para la ejecución del antiguo proyecto; pero frente a éste tendría una superficie construida notablemente mayor y un presupuesto considerablemente más alto. Finalmente, la Junta de Construcciones Civiles aprobó el proyecto, aconsejando algunas modificaciones técnicas (red de distribución de agua insuficiente, cálculos de calefacción poco precisos, alcantarillado no óptimo y mala resolución final de las fachadas) $)^{71}$. Realizadas por Javier de Luque las correcciones (17 de julio de 1922), el proyecto definitivo quedó presupuestado en 1.619.818,51 pesetas de ejecución material. Aceptado por el Negociado de Construcciones Civiles en octubre de 1922, el proyecto sería finalmente aprobado por el Consejo de Ministros, dictándose un Real Decreto el 3 de noviembre que libraba un millón de pesetas para las obras (en cuatro partidas anuales de 250.000 pesetas cada una).

No hemos encontrado documentación que explique la razón del abandono del proyecto primitivo en favor de otro nuevo de mayor entidad y de presupuesto más elevado; no obstante, teniendo en cuenta el amplio movimiento de homenaje a Ramón y Cajal con motivo de su jubilación en 1922, parece razonable pensar que se pretendió dotar al Instituto Cajal de un edificio grande y vistoso en lugar de otro modesto, pero de rápida construcción y eficaz diseño. No en vano José Castillejo, secretario de la Junta para la Ampliación de Estudios, decía en respuesta a Gustavo Pittaluga (miembro de la Junta Nacional para Homenaje a Cajal):

«Me dicen que en proyectos de presupuestos se consigna suma mayor, pero nadie sabe si habrá presupuestos ni cuando. Contentémonos con fórmulas modestas y eficaces. Que nos den ahora las 500.000 pesetas y Cajal estará el invierno próximo en su nuevo laboratorio aunque haya que completarlo después con algún otro pequeño crédito.

/.../ Si Uds. fían en un proyecto de luz especial, creo que se equivocan y que, con el mejor deseo y queriendo lo más, nos quedaremos sin lo más y sin lo menos)» ${ }^{72}$.

En los años subsiguientes las obras en el Instituto Cajal continuarían su curso y tras efectuarse el cuarto libramiento parcial en 1925, en 1926 se establecieron dos

\footnotetext{
71 Véase: Informe de la Junta Facultativa de Construcciones Civiles, fechado el 7 de julio de 1922. Ibidem.

72 Cfr.: Carta de José Castillejo a Gustavo Pittaluga, el 21 de marzo de 1922. Expediente de Santiago Ramón y Cajal. Archivo de la Junta para la Ampliación de Estudios e Investigaciones Científicas. Residencia de Estudiantes, Madrid.
} 
nuevas partidas, para los años 1926 y 1927, que completaban el presupuesto originariamente fijado ${ }^{73}$.

Posteriormente, en noviembre de 1927, el arquitecto informaba de la realización de modificaciones en el proyecto original (algunas de notable importancia, como la construcción de un sub-sótano no previsto inicialmente) y la necesidad de obras complementarias con un presupuesto «que no bajará de 500.000 a 600.000 pese$\operatorname{tas}^{74}$. Habría que esperar hasta febrero de 1929, para que el arquitecto remitiera un presupuesto detallado que fue transmitido a la Junta Facultativa de Construcciones Civiles.

La Junta informaba, con notable frialdad rayana en la indignación, que gran parte de las obras incluidas en el presupuesto ya habían sido ejecutadas (necesariamente habrían de serlo el sub-sótano, las modificaciones en las conducciones de agua, gas o electricidad), y que el documento era más una rendición de cuentas que el presupuesto previo de una obra por realizar ${ }^{75}$. Hay que coincidir con la Junta Facultativa de Construcciones Civiles que el proceso de edificación presentaba serias anomalías y que no son aceptables modificaciones de tal entidad respecto del proyecto original que signifiquen la aparición de una nueva altura en la construcción o el replanteamiento de las redes de suministro. Igualmente anómalas parecen las peticiones del arquitecto para realizar una escalinata de entrada al edificio desde el Paseo de Atocha, para salvar el fuerte desnivel existente; si la escalinata debía realizarse debería haber sido incluida en el proyecto original o en caso contrario haber variado la localización u orientación del edificio.

En cualquier caso, en julio de 1930 se aprobó un presupuesto adicional de 500.000 pesetas, que se fueron librando en sucesivos pagos hasta agosto de 1933. El coste total del edificio según la documentación utilizada ascendió, por tanto, a 2.272.302,14 pesetas; Gonzalo Rodríguez Lafora en un vehemente artículo titulado «El-Instituto Cajal no se acaba de construir», apunta una cantidad superior: 2.421.102 pesetas hasta 1930. No sólo critica Lafora el elevado gasto que supuso la construcción; más amargas son las críticas al arquitecto por no haber respetado el anteproyecto redactado por Juan Negrín (de acuerdo con Cajal y sus discípulos) sobre las especificaciones del edificio y por haber introducido modificaciones sustanciales en el

\footnotetext{
73 Véase: Minuta del Negociado de Construcciones Civiles al Ministro de Instrucción, fecha 26 de Septiembre de 1926. AGA, Educación, caja n 5404, legajo 13609-6.

74 Véase: Comunicación del arquitecto al Ministerio de Instrucción el 18 de noviembre de 1927. Ibidem

75 Véase: Informe de la Junta Facultativa de Construcciones Civiles, fechado el 29 de abril de 1929. Ibidem
} 
proyecto original a espaldas de Cajal, del Negociado de Construcciones Civiles y de la Junta para la Ampliación de Estudios ${ }^{76}$.

El traslado del Instituto Cajal al nuevo edificio se realizó en 1932, ante el estado prácticamente ruinoso de las dependencias ocupadas en el Museo Antropológico ${ }^{77}$. De la nueva sede del Instituto hace una estupenda descripción Fernando de Castro:

\footnotetext{
«El nuevo edificio del Instituto Cajal era de grandes dimensiones: cuatro plantas y un subsótano - «un magnífico palacio», como decía don Santiago--, aunque fuese horrendo por fuera, desproporcionado en su conjunto y con grandes espacios perdidos en su interior. En cada planta había numerosas habitaciones o cuartos de trabajo, amplísimos - muchos de ellos tenían una superficie que oscilaba entre los 70 y los 100 metros cuadrados- y con gran altura de techo - unos 5 metros--, destinados a los ayudantes y becarios. Además disponía de un espléndido salón, con grandes ventanales, dedicados a la biblioteca, /.../ En fin una cátedra, para conferencias y cursos, y una sala de juntas, ambas magníficas, completaban el Instituto» ${ }^{78}$.
}

En los años siguientes el Instituto Cajal estaba destinado a convertirse en un gran centro de investigación sobre los más variados aspectos de las Neurociencias y contaría con laboratorios de neurofisiología, neurohistología normal y patológica, una clínica neurológica, servicios de neurocirugía,... etc ${ }^{79}$. Desgraciadamente este ambicioso proyecto quedo frustrado por el estallido de la Guerra Civil en el verano de 1936.

\section{CONCLUSIONES}

En la segunda mitad del siglo XVIII el desarrollo urbano de Madrid supuso la superación del antiguo recinto de la ciudad y determinó el establecimiento de nuevas vías con un patrón urbanístico novedoso. El Paseo del Prado es el ejemplo más notable del desarrollo dieciochesco de la ciudad. Muy significativamente en torno a este eje se establecieron las más notables instituciones científicas del período ilustrado: Real Jardín Botánico, Academia de Ciencias, Observatorio Astronómico, etc., consti-

76 Véase RodríGuez LAFORA, G. (1931), pp.8-9.

77 Véase: Informe del Comité de Patronato de los Museos, Nacional de Ciencias Naturales, Antropológico y Jardín Botánico, fechado el 2 de diciembre de 1933. AGA, Educación, caja $\mathrm{n}^{\circ} 5408$, legajo 13613-1.

78 Cfr. F. DE CASTRO (1981), «Tello, discípulo de Cajal», en Cajal y la Escuela Neurológica española, Editorial de la Universidad Complutense, Madrid, pp.119.

79 Ibidem, pp.120-121. 
tuyendo el núcleo docente e investigador más importante de la ciudad hasta entrado el siglo XX.

Las construcciones científicas de esta área enfrentaron iguales vicisitudes que el desarrollo científico español del siglo XVIII. El retraimiento de la política reformista en la última década del siglo determinó una deceleración en el ritmo de las obras (en el caso de la Academia o el Observatorio Astronómico) o su suspensión definitiva (por ejemplo, el Hospital General). El estallido de la Guerra de la Independencia en 1808 determinó la total interrupción de la política de construcciones, completando así la trágica ruptura del desarrollo intelectual y científico vivido en la segunda mitad del siglo XVIII.

Durante gran parte del siglo XIX la construcción de instituciones científicas en el área del Paseo del Prado y de Atocha fue muy escasa (sólo cabe reseñar la Facultad de Medicina y unas obras de ampliación en el Jardín Botánico). No hubo, por tanto, un programa de edificación científica similar al del siglo XVIII. Hay que considerar, también, que el establecimiento y desarrollo de la Estación de Atocha en el cuadrante sud-oriental significó una restricción definitiva a toda posible extensión del núcleo docente-investigador y que el establecimiento de la Universidad Central en San Bernardo supuso el fin del monopolio docente investigador que el núcleo del PradoAtocha había venido ejerciendo.

Cuando durante la Restauración se retomó la iniciativa constructora en la zona, las nuevas construcciones se proyectaron sobre el terreno del Jardín Botánico, que sufrió una merma importante de su extensión. Desgraciadamente los recortes sobre la superficie del Jardín no se compensaron con el establecimiento de institutos científicos: la proyectada Escuela de Artes y Oficios se transformó en sede del Ministerio de Fomento y los diversos proyectos para la construcción de una Facultad de Ciencias y Museo de Ciencias Naturales no llegaron a realizarse.

En el primer tercio del siglo XX las obras se limitarían a actuaciones puntuales sobre el Jardín Botánico o el Museo Antropológico, importantes para la institución afectada, pero poco relevantes para el conjunto. El único gran proyecto constructivo fue el Instituto Cajal, cuya edificación presentó graves irregularidades, que dificultaron la consolidación de la escuela neuro-histológica española y retrasaron la extensión de su actividad a otros aspectos de las neurociencias. Finalmente el estallido de la Guerra Civil en 1936 puso punto final al desarrollo de las instituciones científicas que, mal que bien, se venía produciendo desde finales del siglo XIX. 


\section{LUIS ALFREDO BARATAS DÍAZ}

\section{TABLA I}

Obras en el Real Jardín Botánico de Madrid, entre 1866 y 1936. (Fuente: AGA, Educación. Cajas nº 5340-5342, 5412, 8103-8105, 8108-8109, 8370)

\begin{tabular}{|c|c|c|c|c|}
\hline $\begin{array}{l}\text { FECHA DEL PROYECTO Y } \\
\text { ARQUITECTO }\end{array}$ & $\begin{array}{l}\text { FECHA DE } \\
\text { APROBACIÓN. }\end{array}$ & $\begin{array}{l}\text { DESCRIPCIÓN DE } \\
\text { LA OBRA. }\end{array}$ & PRESUPUesto. & EJEC. \\
\hline $\begin{array}{l}\text { 1-2-1866. } \\
\text { Francisco Jareño. }\end{array}$ & $20-2-1866$ & $\begin{array}{l}\text { Obras de reforma para ex- } \\
\text { posición de objetos de la } \\
\text { expedición al Pacífico. }\end{array}$ & $10.312,63$ & $\mathrm{~S}$ \\
\hline $\begin{array}{l}\text { 19-6-1871. } \\
\text { Arquitecto de la } \\
\text { Universidad de Madrid, ?. }\end{array}$ & 21-6-1871. & $\begin{array}{l}\text { Reedificación de las estu- } \\
\text { fas. }\end{array}$ & $\begin{array}{l}71.762,48+ \\
33.334,84\end{array}$ & $\mathrm{~S}$ \\
\hline $\begin{array}{l}\text { 7-9-1875. } \\
\text { Francisco Jareño. }\end{array}$ & $12-10-1875$ & $\begin{array}{l}\text { Obras de acondicionamien- } \\
\text { to de las estu-fas. }\end{array}$ & $11.164,47$ & $\mathrm{~S}$ \\
\hline $\begin{array}{l}\text { 10-7-1885. } \\
\text { M. Belmás. }\end{array}$ & $10-7-1885$ & $\begin{array}{l}\text { Cerramiento de la valla } \\
\text { Pza. Murillo. }\end{array}$ & $47.413,38$ & $\mathrm{~N}$ \\
\hline n.c. & $25-8-1886$ & $\begin{array}{l}\text { Reparación desperfectos } \\
\text { causados por tem-poral. }\end{array}$ & $44.037,52$ & $\mathrm{~S}$ \\
\hline $\begin{array}{l}7-6-1887 . \\
\text { E. Saavedra. }\end{array}$ & $9-7-1887$ & $\begin{array}{l}\text { Cerramiento de la valla } \\
\text { Pza Murillo. }\end{array}$ & $98.196,22$ & $\mathrm{~S}$ \\
\hline No consta. & $19-6-1888$ & Reparación estufa 'vieja'. & $5.782,57$ & $\mathrm{~S}$ \\
\hline $\begin{array}{l}\text { s.f. } \\
\text { J. Ortiz. }\end{array}$ & $29-10-1891$. & Reparación de estufas. & $4.967,82$ & $\mathrm{~S}$ \\
\hline $\begin{array}{l}\text { 9-6-1894. } \\
\text { R. Velázquez. }\end{array}$ & $5-7-1894$ & $\begin{array}{l}\text { Demolición molino de } \\
\text { agua. Conexión a la red } \\
\text { distribución agua. }\end{array}$ & $2.264,25$ & $\mathrm{~S}$ \\
\hline $\begin{array}{l}\text { 16-11-1895. } \\
\text { José Ortiz. }\end{array}$ & $24-11-1895$ & $\begin{array}{l}\text { Obras de reparación en la } \\
\text { Biblioteca. }\end{array}$ & $2.753,16$ & $\mathrm{~S}$ \\
\hline $\begin{array}{l}\text { 20-7-1895. } \\
\text { J. Urioste. }\end{array}$ & $24-8-1895$ & $\begin{array}{l}\text { Cerramiento valla calle } \\
\text { Claudio Moyano. }\end{array}$ & $\begin{array}{l}195.344,10+ \\
20.273,67\end{array}$ & $\mathrm{~S}$ \\
\hline $\begin{array}{l}\text { 7-5-1896. } \\
\text { J. Urioste. }\end{array}$ & $16-5-1896$ & $\begin{array}{l}\text { Derribo depósito de agua. } \\
\text { Construcción de otro nue- } \\
\text { vo. }\end{array}$ & $8.711,43$ & $S$ \\
\hline $\begin{array}{l}\text { 18-7-1896. } \\
\text { J. Ortiz. }\end{array}$ & $27-7-1896$ & $\begin{array}{l}\text { Reparaciones en las casetas } \\
\text { de jardineros. }\end{array}$ & $1.267,35$ & $\mathrm{~S}$ \\
\hline 212 & & & \multicolumn{2}{|c|}{ Asclepio-Vol. XLVIII-1-1996 } \\
\hline
\end{tabular}


EL NÚCLEO DE INSTITUCIONES CIENTÍFICAS MATRITENSES EN EL PASEO DEL PRADO

TABLA I (Continuación)

\begin{tabular}{|c|c|c|c|c|}
\hline $\begin{array}{l}\text { FECHA DEL PROYECTOY } \\
\text { ARQUITECTO }\end{array}$ & $\begin{array}{c}\text { FECHA DE } \\
\text { APROBACIÓN. }\end{array}$ & $\begin{array}{l}\text { DESCRIPCIÓN DE } \\
\text { LA OBRA. }\end{array}$ & Presupuesto. & EJEC. \\
\hline $\begin{array}{l}\text { 30-6-1897. } \\
\text { J. Urioste. }\end{array}$ & $5-7-1897$ & $\begin{array}{l}\text { Puerta superior del Jardín. } \\
\text { Obras de con-solidación de } \\
\text { las estu-fas. }\end{array}$ & $\begin{array}{l}20.926+ \\
14.583,33\end{array}$ & S \\
\hline $\begin{array}{l}\text { 3-2-1898. } \\
\text { J. Ortiz. }\end{array}$ & $15-2-1898$ & $\begin{array}{l}\text { Reparaciones en la Biblio- } \\
\text { teca. }\end{array}$ & $2.390,50$ & $S$ \\
\hline $\begin{array}{l}23-5-1898 . \\
\text { J. Ortiz. }\end{array}$ & $30-5-1898$ & $\begin{array}{l}\text { Reparaciones en la Biblio- } \\
\text { teca. }\end{array}$ & $2.190,50$ & $S$ \\
\hline $\begin{array}{l}28-5-1900 . \\
\text { Iradier. }\end{array}$ & $11-6-1900$ & $\begin{array}{l}\text { Reparaciones en techum- } \\
\text { bres y cornisas. }\end{array}$ & $1.344,50$ & S \\
\hline $\begin{array}{l}\text { s.f. } 1901 . \\
\text { P. Herraiz. }\end{array}$ & 30-7-1901. & $\begin{array}{l}\text { Reparaciones en las estu- } \\
\text { fas. }\end{array}$ & 3.653 & $S$ \\
\hline $\begin{array}{l}\text { 2-8-1901. } \\
\text { P. Herraiz. }\end{array}$ & $24-10-1901$ & Reparaciones en la Cátedra. & $1.157,21$ & $\mathrm{~S}$ \\
\hline $\begin{array}{l}\text { 24-10-1901. } \\
\text { P. Herraiz. }\end{array}$ & - & $\begin{array}{l}\text { Transformación ala del } \\
\text { Pabellón Villanueva aulas } \\
\text { de pintura. }\end{array}$ & 11.860 & $\mathrm{~N}$ \\
\hline $\begin{array}{l}\text { 6-6-1902. } \\
\text { P. Herraiz. }\end{array}$ & 24-7-1902. & $\begin{array}{l}\text { Obras varias de manteni- } \\
\text { miento. Construcción de } \\
\text { servicios públicos. }\end{array}$ & $2.081,36$ & $\mathrm{~S}$ \\
\hline $\begin{array}{l}\text { 4-3-1903. } \\
\text { P. Herraiz. }\end{array}$ & $6-3-1903$ & $\begin{array}{l}\text { Mobiliario y entarimado de } \\
\text { Biblioteca. }\end{array}$ & $3.950,06$ & S \\
\hline $\begin{array}{l}22-9-1905 \text {. } \\
\text { E. Jort. }\end{array}$ & $22-9-1905$ & Pintado de verja exterior. & 24.640 & $\mathrm{~S}$ \\
\hline $\begin{array}{l}18-1-1906 . \\
\text { E. Jort. }\end{array}$ & $17-3-1906$ & $\begin{array}{l}\text { Pabellón de Laboratorio } \\
\text { para Fisiología vegetal. } \\
\text { Caseta vigilante. }\end{array}$ & 13.936 & $N$ \\
\hline $\begin{array}{l}25-2-1907 . \\
\text { E. Repullés. }\end{array}$ & $8-3-1907$ & Reparación de cubiertas. & 1.414 & $\mathrm{~S}$ \\
\hline $\begin{array}{l}\text { s. f. } 5 \text { - } 1908 \text {. } \\
\text { E. Repullés. }\end{array}$ & 18-5-1908. & Caseta para vigilante. & $2.085,39$ & $\mathrm{~S}$ \\
\hline $\begin{array}{l}\text { 1-5-1908. } \\
\text { E. Repullés. }\end{array}$ & $8-6-1908$ & $\begin{array}{l}\text { Pabellón de laboratorio } \\
\text { para Fisiología Vegetal. }\end{array}$ & $11.045,87$ & $\mathrm{~S}$ \\
\hline
\end{tabular}


LUIS ALFREDO BARATAS DÍAZ

TABLA I (Continuación)

\begin{tabular}{|c|c|c|c|c|}
\hline $\begin{array}{l}\text { FECHA DEL PROYECTO Y } \\
\text { ARQUITECTO }\end{array}$ & $\begin{array}{c}\text { FECHA IJE } \\
\text { APROBACIÓN. }\end{array}$ & $\begin{array}{l}\text { DESCRIPCIÓN DE } \\
\text { LA OBRA. }\end{array}$ & Presupuesto. & EJEC. \\
\hline $\begin{array}{l}\text { 30-7-1909. } \\
\text { E. Repullés. }\end{array}$ & 26-8-1908. & $\begin{array}{l}\text { Reparación desperfectos } \\
\text { causados por un incendio } \\
\text { sobre estufas. }\end{array}$ & 1710,80 & $\mathrm{~S}$ \\
\hline $\begin{array}{l}\text { 26-1-1910. } \\
\text { E. Repullés. }\end{array}$ & $24-2-1910$ & $\begin{array}{l}\text { Red de distribución de } \\
\text { agua. }\end{array}$ & $2.362,50$ & $\mathrm{~S}$ \\
\hline $\begin{array}{l}\text { 8-10-1912. } \\
\text { E. Repullés. }\end{array}$ & - & Bocas de riego. & 2662,50 & $\mathrm{~N}$ \\
\hline $\begin{array}{l}\text { 12-10-1917. } \\
\text { E. Repullés. }\end{array}$ & - & $\begin{array}{l}\text { Laboratorios sobre el } \\
\text { Pabellón Villanueva. }\end{array}$ & $152.142,29$ & $\mathrm{~N}$ \\
\hline $\begin{array}{l}\text { 19-6-1920. } \\
\text { P. Muguruza. }\end{array}$ & $3-8-1920$ & $\begin{array}{l}\text { Reparaciones varias y ur- } \\
\text { gentes: estufa, cátedras,... } \\
\text { etc. }\end{array}$ & $24.866,47$ & $\mathrm{~S}$ \\
\hline $\begin{array}{l}\text { 10-8-1920. } \\
\text { P. Muguruza. }\end{array}$ & $19-8-1920$ & Reparación de cubiertas. & $2.666,22$ & $\mathrm{~S}$ \\
\hline $\begin{array}{l}\text { 31-8-1920. } \\
\text { P. Muguruza. }\end{array}$ & $20-9-1920$. & Mobiliario para las estufas. & 1364 & $\mathrm{~S}$ \\
\hline $\begin{array}{l}\text { 31-8-1920. } \\
\text { P. Muguruza. }\end{array}$ & $28-9-1920$ & $\begin{array}{l}\text { Modificación de una } \\
\text { atarjea. }\end{array}$ & $3.984,89$ & $\mathrm{~S}$ \\
\hline $\begin{array}{l}\text { 15-12-1920. } \\
\text { P. Muguruza. }\end{array}$ & $4-1-1921$ & $\begin{array}{l}\text { Reparación de caseta de } \\
\text { jardineros. Obras de im- } \\
\text { permeabilización. }\end{array}$ & $23.705,60$ & $\mathrm{~S}$ \\
\hline $\begin{array}{l}28-5-1921 . \\
\text { P. Muguruza. }\end{array}$ & $25-6-1921$ & Obras en una atarjea. & $12.966,90$ & $\mathrm{~S}$ \\
\hline $\begin{array}{l}28-12-1921 . \\
\text { P. Muguruza. }\end{array}$ & 27-9-1922. & $\begin{array}{l}\text { Obras de Laboratorios so- } \\
\text { bre el Pabellón Villanueva. }\end{array}$ & $20.594,42$ & $\mathrm{~N}$ \\
\hline $\begin{array}{l}\text { 5-12-1922. } \\
\text { P. Muguruza. }\end{array}$ & $11-1-1924$ & $\begin{array}{l}\text { Obras de Laboratorios so- } \\
\text { bre el Pabellón Villanueva. }\end{array}$ & 25.000 & $\mathrm{~N}$ \\
\hline $\begin{array}{l}\text { 17-7-1924. } \\
\text { P. Muguruza. }\end{array}$ & 10-11-1924. & $\begin{array}{l}1^{a} \text { fase de obras de repara- } \\
\text { ción en el Pabellón Villa- } \\
\text { nueva. }\end{array}$ & 24.873 & $\mathrm{~S}$ \\
\hline $\begin{array}{l}\text { 17-7-1924. } \\
\text { P. Muguruza. }\end{array}$ & - & $\begin{array}{l}2^{a} \text { fase de obras de repara- } \\
\text { ción en el Pabellón Villa- } \\
\text { nueva. }\end{array}$ & $24.949,46$ & $\mathrm{~N}$ \\
\hline
\end{tabular}


TABLA I (Continuación)

\begin{tabular}{|c|c|c|c|c|}
\hline $\begin{array}{l}\text { FECHA IJEL PROYECTO Y } \\
\text { ARQUITECTO }\end{array}$ & $\begin{array}{c}\text { FECHA DE } \\
\text { APROBACIÓN. }\end{array}$ & $\begin{array}{l}\text { DESCRIPCIÓN IDE } \\
\text { LA OBRA. }\end{array}$ & Presupuesto. & EJEC. \\
\hline $\begin{array}{l}\text { 17-7-1924. } \\
\text { P. Muguruza }\end{array}$ & - & $\begin{array}{l}3^{a} \text { fase de obras de repara- } \\
\text { ción en el Pabellón Villa- } \\
\text { nueva. }\end{array}$ & $23.969,81$ & $N$ \\
\hline $\begin{array}{l}\text { 17-7-1924. } \\
\text { P. Muguruza. }\end{array}$ & $21-2-1927$ & $\begin{array}{l}2^{a} \text { y } 3^{a} \text { fases de obras de } \\
\text { reparación en el Pabellón } \\
\text { Villanueva. }\end{array}$ & $29.404,32$. & $\mathrm{S}$ \\
\hline $\begin{array}{l}\text { 9-3-1927. } \\
\text { P. Muguruza. }\end{array}$ & 5-4-1927.- & $\begin{array}{l}\text { Reconstrucción de la } \\
\text { Estufa del Jardinillo. }\end{array}$ & $42.462,37$ & $\mathrm{~S}$ \\
\hline $\begin{array}{l}\text { s.f. } 8-1927 . \\
\text { P. Muguruza. }\end{array}$ & - & $\begin{array}{l}\text { Construcción de Laborato- } \\
\text { rios sobre el Pabellón } \\
\text { Villanueva. }\end{array}$ & $48.592,57$ & $N$ \\
\hline $\begin{array}{l}27-12-1927 . \\
\text { P. Muguruza. }\end{array}$ & 24-2-1928. & $\begin{array}{l}\text { Obras complementarias de } \\
\text { reparación en el Pabellón } \\
\text { Villanueva. }\end{array}$ & 24.745 & $\mathrm{~S}$ \\
\hline $\begin{array}{l}\text { 15-5-1929. } \\
\text { P. Muguruza. }\end{array}$ & $6-7-1929$ & $\begin{array}{l}\text { Arreglo general de la Cá- } \\
\text { tedra. Reparaciones en } \\
\text { estufas y paseos. }\end{array}$ & $29.722,94$ & $\mathrm{~S}$ \\
\hline $\begin{array}{l}\text { 14-5-1929. } \\
\text { P. Muguruza. }\end{array}$ & s.f. 1929. & $\begin{array}{l}\text { Colocación de bancos de } \\
\text { piedra en los paseos. }\end{array}$ & $19.255,51$ & $\mathrm{~S}$ \\
\hline $\begin{array}{l}\text { 3-3-1930. } \\
\text { P.Muguruza. }\end{array}$ & $25-6-1930$ & $\begin{array}{l}\mathrm{I}^{\mathrm{a}} \text { fase de obras de repara- } \\
\text { ción en la Estufa grande. }\end{array}$ & $24.894,58$ & $\mathrm{~S}$ \\
\hline $\begin{array}{l}\text { 21-4-1930. } \\
\text { P. Muguruza. }\end{array}$ & 25-6-1930. & $\begin{array}{l}2^{\mathrm{a}} \text { fase de obras de repara- } \\
\text { ción en la Estufa grande. }\end{array}$ & $24.640,91$ & $\mathrm{~S}$ \\
\hline $\begin{array}{l}5-11-1930 . \\
\text { P. Muguruza. }\end{array}$ & $10-2-1931$ & $\begin{array}{l}\text { Obras de Laboratorios so- } \\
\text { bre el Pabellón Villanueva. }\end{array}$ & $44.389,64$ & $\mathrm{~S}$ \\
\hline $\begin{array}{l}\text { 11-2-1931. } \\
\text { P. Muguruza. }\end{array}$ & $2-5-1932$ & $\begin{array}{l}\text { Obras de ampliación de la } \\
\text { Estufa Grande. }\end{array}$ & $49.946,12$ & $\mathrm{~S}$ \\
\hline $\begin{array}{l}25-11-1932 . \\
\text { P. Muguruza. }\end{array}$ & $7-2-1933$ & $\begin{array}{l}\text { Obras de Laboratorios so- } \\
\text { bre el Pabellón Villanueva. }\end{array}$ & $44.389,64$ & $\mathrm{~S}$ \\
\hline $\begin{array}{l}\text { 3-2-1933. } \\
\text { P. Muguruza. }\end{array}$ & $20-11-1933$ & $\begin{array}{l}\text { Obras de Laboratorios so- } \\
\text { bre el Pabellón Villanueva. }\end{array}$ & $49.277,29$ & Parc. \\
\hline $\begin{array}{l}\text { 16-3-33. } \\
\text { P. Muguruza. }\end{array}$ & - & $\begin{array}{l}\text { Reparación y pavimenta- } \\
\text { ción de paseos. }\end{array}$ & $48.614,91$ & $?$ \\
\hline
\end{tabular}


LUIS ALFREDO BARATAS DÍAZ

TABLA I (Continuación)

\begin{tabular}{|l|l|l|l|l|}
\hline $\begin{array}{l}\text { FECHA DEL PROYECTOY } \\
\text { ARQUITECTO }\end{array}$ & $\begin{array}{c}\text { FECHA DE } \\
\text { APROBACIÓN. }\end{array}$ & \multicolumn{1}{|c|}{$\begin{array}{c}\text { DESCRIPCIÓN IDE } \\
\text { LA OBRA. }\end{array}$} & PRESUPUESTO. & EJEC. \\
\hline $\begin{array}{l}28-9-1933 . \\
\text { P. Muguruza. }\end{array}$ & $19-3-1934$. & $\begin{array}{l}\text { Obras varias, mobiliario,... } \\
\text { etc. }\end{array}$ & $28.135,20$ & $\mathrm{~S}$ \\
\hline $\begin{array}{l}\text { 7-4-1936. } \\
\text { M. Sanchez Arcas. }\end{array}$ & $2-5-1936$. & $\begin{array}{l}\text { Obras de Laboratorios } \\
\text { sobre el Pabellón Villanue- } \\
\text { va. }\end{array}$ & $49.537,44$ &. \\
\hline
\end{tabular}

\section{TABLA II}

Obras en el Museo Antropológico entre 1912 y 1933. (Fuente: AGA, Educación. Cajas n 4959, 5408, 5412, 8197).

\begin{tabular}{|c|c|c|c|c|}
\hline $\begin{array}{l}\text { FECHA DEL PROYECTO Y } \\
\text { ARQUITECTO }\end{array}$ & $\begin{array}{l}\text { FECHA DE } \\
\text { APROBACIÓN. }\end{array}$ & $\begin{array}{l}\text { DESCRIPCIÓN IDE } \\
\text { LA OBRA. }\end{array}$ & Presupuesto. & EJEC. \\
\hline $\begin{array}{l}\text { 4-9-1912. } \\
\text { E. Repullés. }\end{array}$ & $24-2-1913$. & Reparación de cubiertas. & $5.221,92$ & S. \\
\hline $\begin{array}{l}\text { 4-10-1913. } \\
\text { E. Repullés. }\end{array}$ & $27-2-1917$. & Reparaciones en el tejado. & 214,55 & S. \\
\hline $\begin{array}{l}\text { '26-2-1914. } \\
\text { E. Repullés. }\end{array}$ & $18-5-1914$ & $\begin{array}{l}\text { Reparación daños por ven- } \\
\text { daval. }\end{array}$ & $1.802,95$ & S. \\
\hline $\begin{array}{l}\text { 8-10-1914. } \\
\text { E. Repullés. }\end{array}$ & $\begin{array}{l}22-11-1915 y \\
8-2-1915\end{array}$ & Reparaciones en el tejado. & 405,38 & S. \\
\hline $\begin{array}{l}\text { 26-9-1914. } \\
\text { E. Repullés. }\end{array}$ & $\begin{array}{l}6-11-1914 \text { y } \\
24-5-1915\end{array}$ & $\begin{array}{l}\text { Reparación de filtraciones } \\
\text { de agua. }\end{array}$ & $2.065,38$ & S. \\
\hline $\begin{array}{l}\text { 5-7-1915. } \\
\text { E. Repullés. }\end{array}$ & $31-12-1915$ & $\begin{array}{l}\text { Obras de acondicionamien- } \\
\text { to en el Laboratorio de } \\
\text { Análisis Químico. }\end{array}$ & $6.380,70$ & S. \\
\hline $\begin{array}{l}\text { 11-2-1916. } \\
\text { E. Repullés. }\end{array}$ & $17-4-1916$ & $\begin{array}{l}\text { Mobiliario e instrumental } \\
\text { científico en el Laboratorio } \\
\text { de Análisis. Construcción } \\
\text { terraza sobre el Laboratorio } \\
\text { de Investigaciones Biológi- } \\
\text { cas. }\end{array}$ & $12.748,33$ & S. Parc? \\
\hline 16 & & & \multicolumn{2}{|c|}{ Asclepio-Vol. XLVIII-1-1996 } \\
\hline
\end{tabular}


TABLA II (Continuación)

\begin{tabular}{|c|c|c|c|c|}
\hline $\begin{array}{l}\text { FECHA DEL PROYECTO Y } \\
\text { ARQUITECTO }\end{array}$ & $\begin{array}{l}\text { FECHA DE } \\
\text { APROBACIÓN. }\end{array}$ & $\begin{array}{l}\text { DESCRIPCIÓN IJE } \\
\text { LA OBRA. }\end{array}$ & Presupuesto. & EJEC. \\
\hline $\begin{array}{l}\text { 19-12-1918. } \\
\text { J. Luque. }\end{array}$ & $1-6-1919$ & $\begin{array}{l}1^{\mathrm{a}} \text { fase reparación del } \\
\text { tejado. }\end{array}$ & 10.000 & S. \\
\hline $\begin{array}{l}\text { 3-12-1919. } \\
\text { J. Luque. }\end{array}$ & $29-7-1920$. & $\begin{array}{l}\text { Reparación de cubiertas. } \\
\text { Construcción de terraza } \\
\text { sobre el Laboratorio de Inv. } \\
\text { Biológicas. }\end{array}$ & 7.531 & S. \\
\hline $\begin{array}{l}\text { 4-6-1920. } \\
\text { J. Luque. }\end{array}$ & $12-6-1920$. & $\begin{array}{l}2^{\circ} \text { fase reparación del } \\
\text { tejado. }\end{array}$ & $24.991,03$ & S. \\
\hline $\begin{array}{l}\text { 21-7-1920. } \\
\text { J. Luque. }\end{array}$ & $20-11-1920$ & $\begin{array}{l}\text { Reparación de daños } \\
\text { causados por un temporal. }\end{array}$ & $2.820,37$ & S. \\
\hline $\begin{array}{l}\text { 4-4-1922. } \\
\text { J. Luque. }\end{array}$ & $12-5-1922$ & $\begin{array}{l}3^{a} \text { fase reparación del } \\
\text { tejado. }\end{array}$ & $10.184,96$ & S. \\
\hline $\begin{array}{l}\text { 6-8-1924. } \\
\text { J. Luque. }\end{array}$ & $7-7-1925$ & $\begin{array}{l}\text { Obras en la sala general. } \\
\text { Reparación desperfectos } \\
\text { resultado de la reparación } \\
\text { del tejado. }\end{array}$ & $21.14-5,39$ & S. \\
\hline $\begin{array}{l}\text { I-10-1931. } \\
\text { J. Luque. }\end{array}$ & 18-2-1932. & Instalación extintores. & $2.435,62$ & S. \\
\hline $\begin{array}{l}\text { 5-12-1932. } \\
\text { J. Luque. }\end{array}$ & - & $\begin{array}{l}\text { Reforma de las cubiertas, } \\
\text { revocado de las fachadas. }\end{array}$ & $49.998,22$ & $?$ \\
\hline $\begin{array}{l}\text { 25-3-1933. } \\
\text { J. Luque. }\end{array}$ & $4-12-1933$. & $\begin{array}{l}\text { Reparación piso primero } \\
\text { para destinarlo a Laborato- } \\
\text { rio de Paleontología. }\end{array}$ & $49.978,97$ & $?$ \\
\hline $\begin{array}{l}\text { 13-12-1933. } \\
\text { M. Sánchez Arcas. }\end{array}$ & - & $\begin{array}{l}\text { Proyecto general de obras } \\
\text { en el Museo. }\end{array}$ & - & $\mathrm{N}$. \\
\hline
\end{tabular}

